\title{
CARACTERIZACIÓN DE LAS PRÁCTICAS RECREATIVAS DE LOS NIÑOS Y NIÑAS DE LA LUDOTECA DEL BARRIO UVAL POR MEDIO DE ESPACIOS DE PARTICIPACIÓN INFANTIL ${ }^{1}$
}

\author{
Por, Cindy Joulieth Castro Ramírez. ${ }^{2}$
}

\section{Resumen.}

Éste artículo analiza las prácticas, preferencias y necesidades recreativas que los niños y niñas beneficiarios de la Ludoteca del barrio Uval manifestaron a través de un espacio de participación infantil e identifica las metodologías que se emplearon para incluir la voz de los niños y niñas en la formulación de la Política Pública de recreación para Bogotá 2009 -2019 y de los programas recreativos de la localidad de Usme. Se inició con la construcción del estado del arte de las temáticas abordadas, la revisión documental, tanto conceptual como normativa de las dos grandes categorías de la investigación: recreación, participación infantil, diseño y formulación de políticas públicas y su relación con el desarrollo humano integral; eje central de la Maestría en Planeación para el Desarrollo; lo cual dio insumos para el diseño metodológico y el trabajo de campo que incluyó la aplicación de dos entrevistas semiestructuradas a funcionarios del Instituto Distrital de Recreación y Deporte, quince encuestas aplicadas a los acudientes de los niños y niñas y un taller que empleó como instrumento el juego: "Re-creando mi mundo", contando con la población total de quince niños y niñas entre las edades de 6 a 2 años beneficiarios de

\footnotetext{
${ }^{1}$ Artículo científico que presenta el informe del proceso de investigación para optar por el título de Maestra en Planeación para el Desarrollo de la Universidad Santo Tomás. Agradecimiento a los maestros que acompañaron este proceso: Edson Louidor, Jenny Cortes y Doris Herrera; a la Unidad de Proyección Social de la USTA, la cual articula los procesos de la Ludoteca del barrio Uval y a los niños y niñas que permitieron escuchar sus voces, plasmando sus sueños, sus sentires y su proyección de un territorio pensado en ellos y en sus comunidades desde la resignificación de su derecho a la recreación.

${ }^{2}$ Profesional de Cultura Física, Deporte y Recreación. Coordinadora del Departamento de Promoción y Bienestar Universitario de la Universidad Santo Tomás, lidera procesos de planeación, gestión, ejecución y evaluación de programas deportivos, culturales y de promoción de la salud. cindyjcastror@gmail.com
} 
la Ludoteca del barrio Uval. Como técnicas de análisis se empleó el análisis documental, estadístico y de contenido.

Los resultados arrojados indican que los sectores de la recreación en sus prácticas y preferencias se enfocan en la deportiva desde la natación y el fútbol, en la artística cultural con el baile, el canto y la escritura para las niñas, en la recreación ambiental a partir del cuidado a la naturaleza, turística desde el anhelo de visitar sus lugares de procedencia y de pasear en familia y comunitaria desde el encuentro en el juego con sus familias y amigos. Las prácticas y preferencias concretas nos lleva a concluir la influencia de su contexto socioeconómico, el cual puede inferir por las oportunidades que oferta su territorio y su modo de vida y los imaginarios sociales que se han construido desde sus familias en las prácticas recreativas. En lo que refiere a la metodología de participación empleada en el diseño y formulación de la política pública de deporte, recreación y actividad física para Bogotá 2009-2019 se identifica la propuesta de la metodología "la pelota está en tus manos" donde fueron escuchadas las voces de los niños y niñas de forma indirecta, al ser mediadas por la información que expresaban los padres que llevaban a sus hijos (as) y por otra parte se identifica un diseño de programas recreativos (top-down) estipulados desde las instituciones distritales y locales, realidad que invita a re-crear las metodologías, escenarios y mecanismos que la participación infantil tiene como reto en un Estado de derecho como lo es el colombiano.

Palabras claves: recreación, participación infantil, localidad de Usme, política pública de recreación en Bogotá.

\section{Abstract.}

This article analyzes the practices, preferences and recreational needs that the children who benefited from the Ludoteca in the Uval neighborhood expressed through a space of child participation and identifies the methodologies used to include the voice of children in the formulation Of the Public Policy of recreation for Bogota 2009 -2019 and of the recreational programs of the town of Usme. It began with the construction of the state of the art of the themes addressed, documentary revision, both conceptual and normative of 
the two major categories of research: recreation, child participation, design and formulation of public policies and its relationship with integral human development ; Central axis of the Master in Planning for Development; Which gave inputs to the methodological design and fieldwork that included the application of two semi-structured interviews to officials of the District Recreation and Sport Institute, fifteen surveys applied to the children's attendants, and a workshop that used as an instrument the Game: "Recreating my world", counting on the total population of fifteen children between the ages of 6 to 12 years beneficiaries of the Ludoteca of the neighborhood Uval. As analysis techniques, documentary, statistical and content analysis were used.

The results show that the sectors of recreation in their practices and preferences focus on sports from swimming and football, cultural arts with dancing, singing and writing for girls, environmental recreation from Care for nature, tourism from the desire to visit their places of origin and to walk in family and community from the encounter in the game with their families and friends. Concrete practices and preferences lead us to conclude the influence of their socioeconomic context, which can be inferred by the opportunities offered by their territory and their way of life and the social imaginaries that have been constructed from their families in recreational practices. Regarding the participation methodology used in the design and formulation of the public policy for Sports, Recreation and Physical Activity for Bogota 2009-2019, the methodology of the "ball is in your hands" methodology is identified. Children's voices in an indirect way, being mediated by the information expressed by parents who took their children and on the other hand identifies a design of top-down recreational programs. Stretched from the district institutions And localities Reality that invites to re-create the methodologies, scenarios and mechanisms that the participation of children has as a challenge in a State of law as is the Colombian.

Keywords: recreation, child participation, Usme locality, public policy for recreation in Bogotá. 


\section{Introducción.}

A pesar de los reconocimientos que otorga la ley al derecho a la recreación y al aprovechamiento del tiempo libre, como lo evidencia el artículo 52 de la Constitución Política de Colombia de 1991, la Ley 181, el Plan decenal del deporte, la recreación, la educación física y la actividad física 2009 -2019, y a nivel internacional la Declaración Universal de los Derechos Humanos y la Asamblea General de las Naciones Unidas, aun no se hace conciencia sobre su importancia en la vida de las personas, en donde el goce de estos derechos se tornan difusos en los procesos de desarrollo humano integral, especialmente en la niñez.

En este contexto, a nivel distrital el Plan de Desarrollo ${ }^{3}$ 2012-2016: Bogotá Humana, resaltó que "La niñez debe gozar a plenitud de la totalidad de los derechos: a la salud, a la educación, a la alimentación, al afecto, al juego y a la vida” (Alcaldía Mayor de Bogotá D.C., 2012, p. 9) y planteó entre sus estrategias "Reconocer la dimensión específica de la cultura, el arte, la actividad física, la recreación y el deporte” (Alcaldía Mayor de Bogotá D.C., 2012, p. 30). Por otra parte, el Plan de Desarrollo 2016-2020: Bogotá mejor para todos, expone:

En esta Bogotá, los niños y niñas son la prioridad y gozan de condiciones para hacer valer sus derechos, tener oportunidades y hacer realidad la vida que desean. La primera infancia ha sido prioridad y hoy los niños y niñas gozan del derecho al cuidado calificado, la promoción de hábitos saludables, la salud, la alimentación, la educación inicial de calidad, la cultura, el uso creativo del tiempo libre y la protección frente a situaciones o condiciones de vulnerabilidad. (Alcaldía Mayor de Bogotá D.C., 2016, p. 57)

Plan que da continuidad a la prioridad que representa para el gobierno distrital los niños y niñas, por tal motivo, dichos Planes de Desarrollo nos hacen reflexionar sobre la

\footnotetext{
${ }^{3}$ El plan de desarrollo es el principal instrumento de la gestión de la política pública de las entidades
} territoriales. (Departamento Nacional de Planeación, 2012, p. 6) 
importancia que se ésta otorgando a los niños y niñas como sujetos de derecho y por otro lado, del goce de los derechos de la niñez, entre ellos la recreación. Y es aquí donde se inicia a vislumbrar una realidad: el lugar que se le está otorgando a la participación infantil en dicho proceso. Si bien son sujetos de derecho, en consecuencia son actores participativos y como tales se deben tener en cuenta en el proceso de diseño, formulación e implementación de las políticas públicas de los temas que los convocan, escenario deseado desde un enfoque de diseño y formulación de abajo hacia arriba (bottom-up) y no sólo técnico y experto.

La participación es la base de la democracia puesto que supone el común acuerdo de las voces del pueblo para definir la ruta que se debe trazar en el tan anhelado bien común, principio de la Polis del cual nos hablaba Aristóteles, pues bien, si partimos del principio constitucional del artículo 1 que nos dice que Colombia es una "República unitaria, descentralizada, con autonomía de sus entidades territoriales, democrática, participativa y pluralista" (Constitución Política de Colombia, 1991, s/p). Si los niños y niñas son ciudadanos, actores de sus derechos, podemos resaltar la importancia que tiene la participación infantil en el diseño y formulación de Políticas Públicas para una nación más incluyente que reconoce a los ciudadanos como actores.

Sin embargo, pese a dicha importancia en las normas, la realidad es otra en lo que refiere a la participación de los niños y niñas en la formulación de las políticas públicas en deporte, recreación y actividad física a nivel distrital, en tanto, como lo expresan los hacedores de políticas (police maker): "un niño de 5, 8 o 10 años, de alguna forma no puede participar de una manera tan activa sin la compañía de sus padres, muchos de ellos estaban acompañados de sus padres y a través de sus padres expresaban sus opiniones"4, "proyectos que nazcan de la institución si los hay pero no donde fomenten la participación ni de acuerdo a lo que los niños digan si no que ya están estipulados desde acá" ${ }^{\circ}$;

\footnotetext{
${ }^{4}$ Respuesta del Lic. Oscar Ruiz, jefe del área de Recreación del IDRD, en la entrevista aplicada por la autora.

${ }^{5}$ Respuesta del Lic. Mario Salinas, coordinador del IDRD en la localidad de Usme, en la entrevista aplicada por la autora.
} 
expresiones que evidencian que la voz de los infantes es interpretada por los adultos y que son las instituciones quienes elaboran las política pública y los programas dirigidos a los niños desde un enfoque de arriba hacia abajo (top-down).

Con este panorama es importante indagar los mecanismos y acciones que se pueden implementar con los niños y niñas para escuchar sus voces, para hacer realidad la participación infantil en el diseño, formulación e implementación de las políticas públicas, por eso esta investigación pretendió evidenciar el papel de la participación infantil en los procesos de planeación para el desarrollo, al involucrar a los niños y niñas, habitantes de la localidad de Usme, que se benefician de la Ludoteca ${ }^{6}$ del barrio Uval, coordinada por el Centro de Proyección Social (CPS) Monte de Galilea ${ }^{7}$.

La Ludoteca y el CPS se ubican en la Unidad de Planeamiento Zonal ${ }^{8}$ (UPZ) Alfonso López, la cual cuenta con insuficiente equipamiento para la población de la zona, de acuerdo a los datos suministrados por el Diagnóstico de los aspectos físicos, demográficos

6 "El concepto de Ludoteca es acuñado en 1934 cuando se abre la primera en Los Ángeles (USA) aunque sólo se extenderá a nivel internacional a partir de 1960, fecha en la que la UNESCO lanza la idea a nivel internacional... Las Ludotecas son instituciones de carácter recreativo - cultural especialmente pensadas para los niños y adolescentes, que tienen como primera misión desarrollar la personalidad a través del juego y el juguete." (Ministerio de Educación, Cultura y Deporte de España, 2003, p. 7-8)

${ }^{7}$ El Centro de Proyección Social (CPS) Monte de Galilea de la Universidad Santo Tomás se encuentra ubicado en Bogotá en la localidad de Usme; gracias al camino abonado por el trabajo pastoral del convento San Alberto de la Orden de Predicadores, que años atrás ha tenido un contacto directo con la comunidad hasta el punto de fundar, establecer y administrar La iglesia Monte de Galilea, en el año 2003, "estudiantes y profesores de las Facultades de Comunicación Social, Sociología, Cultura Física y Psicología realizan sus prácticas y proyectos apoyando procesos de carácter comunitario en la zona. A finales de 2004 se promueve la vinculación de otras Facultades como Derecho, Ingenierías, Filosofía y Administración de Empresas. En ese mismo año y como antesala al trabajo del año 2005 se alquila una sede para el Centro de Proyección Social Monte de Galilea, lugar desde donde se coordinan las actividades con plena participación de las comunidades beneficiarias. Hasta 2006, se habían ido diseñando e implementando, entre otros, proyectos de refuerzo escolar y ocupación del tiempo libre de niños y jóvenes, creación de ludoteca, programa de nutrición para la tercera edad, capacitación en informática y sistemas, capacitación en confecciones, escuela de informática, cursos de electricidad y electrónica básica, consultorios jurídico y psicológico." (González et al, p. 84, 2007). Actualmente, el CPS es un canal de comunicación de doble vía entre los programas académicos y los territorios o comunidades, donde la Universidad ofrece sus servicios a comunidades, en distintos entornos sociales, a través de las prácticas profesionales, investigaciones, extensiones de cátedra y pasantías.

${ }^{8}$ La Unidad de Planeamiento Zonal (UPZ) tiene como propósito definir y precisar el planeamiento del suelo urbano, respondiendo a la dinámica productiva de la ciudad y a su inserción en el contexto regional, involucrando a los actores sociales en la definición de los aspectos de ordenamiento y control normativo a escala zonal.(Secretaria de Planeación Distrital, 2011, p. 9) 
y socioeconómicos, realizado por la Secretaría Distrital de Planeación, donde las variables de la figura 1 llaman la atención en el equipamiento para la cultura, la recreación y el deporte, debido a su baja cobertura o incluso inexistencia, lo cual es una realidad que requiere proponer alternativas creativas que sean factibles con los recursos con los que se cuentan y que permitan materializar un derecho tan importante para el desarrollo humano integral de la niñez, como lo es la recreación.

En el cuadro siguiente se puede observar la relación que hay entre la población y los equipamientos existentes, así como el tipo de equipamientos con los que cuenta cada UPZ. Las UPZ Danubio, Alfonso López y Ciudad Usme presentan la menor cantidad de equipamientos con respecto a su población, ya que figuran con menos de 19 equipamientos por cada 10.000 residentes. (Secretaría Distrital de Planeación Secretaría Distrital de Planeación, 2009, p. 32.)

Figura 1. Número de equipamentos por sector, población, número de equipamentos por cada 10.000 habitantes y cantidad de población por equipamento según UPZ. 2009.

\begin{tabular}{|c|c|c|c|c|c|c|c|c|c|c|c|c|c|c|}
\hline UPZ & 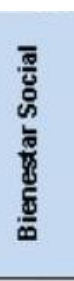 & 胥 & 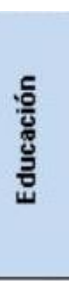 & 疍 & 禀 & 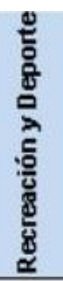 & 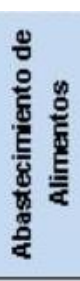 & 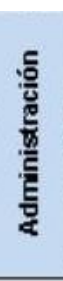 & 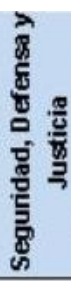 & 尊 & है & 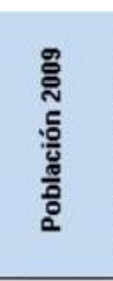 & 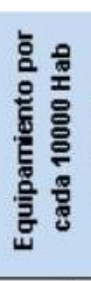 & 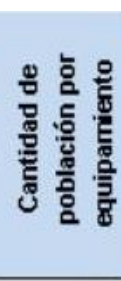 \\
\hline 52 La Flora & 40 & 1 & 5 & 8 & 3 & & & & & & 57 & 18.507 & 31 & 325 \\
\hline 56 Danubio & 39 & 1 & 9 & 5 & 4 & & & & & & 58 & 36.193 & 16 & 624 \\
\hline 57 Gran Yomasa & 245 & 9 & 44 & 27 & 8 & 1 & 2 & 3 & & 5 & 346 & 138.142 & 25 & 399 \\
\hline 58 Comuneros & 195 & 2 & 38 & 14 & 9 & 2 & 1 & & & 1 & 262 & 86.795 & 30 & 331 \\
\hline 59 Alfonso López & 73 & 1 & 11 & 5 & 6 & & & & & & 96 & 54.095 & 18 & 563 \\
\hline 60 Parque Entrenubes & & & & 1 & 1 & & & & & & 2 & 1.948 & N.A & N.A \\
\hline 61 Ciudad Usme & 6 & 3 & 3 & 3 & 1 & & & 3 & & 1 & 24 & 13.496 & 18 & 562 \\
\hline UPR Cerros Orientales y Rio Tunjuelo & & 1 & & & & & & & & & 1 & 170 & N.A & N.A \\
\hline Total Usme & 598 & 18 & 110 & 63 & 32 & 3 & 3 & 6 & 10 & 3 & 846 & 349.346 & 24 & 413 \\
\hline$\%$ & 70,7 & 2,1 & 13,0 & 7,4 & 3,8 & 0,4 & 0,4 & 0,7 & 1,2 & 0,4 & 100 & & & \\
\hline
\end{tabular}

Fuente. Secretaría Distrital de Planeación, 2009.

Con ésta problemática, se formularon los siguientes interrogantes: ¿de qué manera la Política Pública de recreación para Bogotá 2009 -2019 y los programas recreativos de la localidad de Usme incluyen en la formulación la voz de los niños y niñas? y ¿cuáles son las características que se derivan de las prácticas, preferencias y necesidades 
recreativas de los niños y niñas de la Ludoteca del barrio Uval de la Localidad de Usme para diseñar un proyecto recreativo?

Partiendo de este contexto, es importante señalar que si bien la recreación es un derecho, ésta se comprende como un proceso de acción participativa que facilita comprender la vida como una experiencia de felicidad, goce, creación y libertad, siendo dinámica y transformadora en la búsqueda del pleno desarrollo de las potencialidades y dimensiones de la persona, concepción misma que ya nos invita a pensar en la importancia de formular programas que respondan a las preferencias ${ }^{9}$ de los niños y niñas, puesto que las practicas recreativas en su misma concepción responden al principio de libertad.

Por ende, esta investigación analizó las prácticas, preferencias y necesidades recreativas que los niños y niñas beneficiarios de la Ludoteca del barrio Uval manifestaron a través de un espacio de participación infantil como insumo para la construcción de un proyecto recreativo.

Con base en la realidad evidenciada, este artículo presenta cuatro partes que responden al proceso de investigación realizado: discusión y relación de los conceptos de recreación, desarrollo humano integral, participación infantil, diseño y formulación de políticas públicas; diseño metodológico; resultados y recomendaciones y conclusiones.

\footnotetext{
${ }^{9} \mathrm{El}$ concepto de preferencia ha sido empleado especialmente en la economía y estudios de mercados, como lo resalta Mora es: "un elemento fundamental en la teoría microeconómica consiste en cómo los individuos realizan sus decisiones y cómo seleccionan alternativas de un conjunto disponibles de las mismas." (Mora, 2002, p. 23) "Según la versión de la teoría de la utilidad que prevalece en la economía, las preferencias de una persona se pueden decir que son reveladas por sus elecciones. Es decir, por la definición, entre dos alternativas se dice que una persona prefiere lo que él o ella de hecho tiende a elegir... Más aun, es normal y común igualar el bienestar de una persona con la satisfacción de sus preferencias." (Martínez \& París, 2006, p. 76) Siendo entonces el concepto de preferencias, en el marco de las Ciencias Sociales, las cuales nos convocan en esta investigación, la expresión de "los deseos de los individuos, que tienen que ver con su bienestar" (Hernández, 2002, p.168).
} 
Discusión y relación de los conceptos de recreación, desarrollo humano integral, participación infantil, diseño y formulación de políticas públicas.

Iniciemos la presentación de éste marco referencial que dio la orientación conceptual, normativa y contextual de la temática que nos convoca en esta investigación: la recreación, la participación infantil, el diseño y la formulación de Políticas Públicas y sus aportes al desarrollo humano integral, con la invitación al lector para que resignifique el concepto de la recreación, pasando de imaginarios sociales que giran alrededor de la recreación comprendida como la actividad de una fiesta de cumpleaños de niños, para construir una representación que nazca de las experiencias cotidianas que experimentamos al recrearnos, como un proceso que permite nuestro desarrollo humano integral mediado por nuestra libertad y el respeto por el otro y el medio en el que convivimos.

\section{¿Qué se entiende por recreación?}

Resignifiquemos el concepto de recreación, presentando una perspectiva holística de la misma:

La recreación es un medio para la acción social, a partir de la libre elección y el respeto por la libertad de los individuos que conforman una sociedad. De esta manera es mediadora de los procesos de desarrollo humano, donde lo esencial es la comprensión de la realidad del ser humano actual, posibilitando espacios de diversión, de descanso, de participación social, de expresión y socialización de toda su realidad en la perspectiva de ser propiciadora del desarrollo integral. (López, Montes \& Espejo, 2008, p. 23)

Por otra parte, la perspectiva normativa ubica a la recreación como un derecho, partiendo a nivel nacional del reconocimiento que hace la Constitución Política de la República de Colombia en el artículo 52:

El ejercicio del deporte, sus manifestaciones recreativas, competitivas y autóctonas tienen como función la formación integral de las personas, preservar y 
desarrollar una mejor salud en el ser humano. El deporte y la recreación, forman parte de la educación y constituyen gasto público social. Se reconoce el derecho de todas las personas a la recreación, a la práctica del deporte y al aprovechamiento del tiempo libre. El Estado fomentará estas actividades e inspeccionará, vigilará y controlará las organizaciones deportivas y recreativas cuya estructura y propiedad deberán ser democráticas (Constitución Política de la República de Colombia, $1991, \mathrm{~s} / \mathrm{p})$.

Este reconocimiento se hace también evidente en el Plan Decenal del deporte, la recreación, la educación física y la actividad física 2009 -2019 y en el artículo 5 de la Ley 181 de 1995, por la cual por el cual se dictan disposiciones para el fomento del deporte, la recreación, el aprovechamiento del tiempo libre y la educación física y se crea el Sistema Nacional del Deporte, se define la recreación como:

Un proceso de acción participativa y dinámica, que facilita entender la vida como una vivencia de disfrute, creación y libertad, en el pleno desarrollo de las potencialidades del ser humano para su realización y el mejoramiento de la calidad de vida individual y social, mediante la práctica de actividades físicas o intelectuales de esparcimiento $(2009, \mathrm{~s} / \mathrm{p})$.

En lo que refiere al marco normativo para la infancia, La Convención sobre los Derechos del Niño, aprobada en 1989, dispone: "Los Estados partes respetarán y promoverán el derecho del niño a participar plenamente en la vida cultural y artística y propiciarán oportunidades apropiadas, en condiciones de igualdad, de participar en la vida cultural, artística, recreativa y de esparcimiento" (Asamblea General de las Naciones Unidas, 1989, p. 31).

La Ley 1098 de 2006, por la cual se expide el Código de la Infancia y la Adolescencia, en su artículo 30 define el "Derecho a la recreación, participación en la vida cultural y en las artes. Los niños, las niñas y los adolescentes tienen derecho al descanso, esparcimiento, al juego y demás actividades recreativas propias de su ciclo vital y a participar en la vida cultural y las artes" (2006). 
Adicionalmente, la existencia de la recreación en la estructura y funciones del Estado, "obedece a su reconocimiento como derechos fundamentales, sobre la base que contribuyen eficazmente al desarrollo de los pueblos y de las personas" (COLDEPORTES, 2009), estructura que se hila de forma coherente a la perspectiva holística de la recreación.

Para dimensionar los alcances de la recreación, se identifican los sectores en donde interviene, tomando como referencia los propuestos por el Plan nacional de recreación 2004-2009, estos sectores son:

Tabla 1

Sectores de la recreación en Colombia.

\begin{tabular}{|c|c|}
\hline Sector. & aracterísticas. \\
\hline Recreación comunitaria. & Desarrolla metodologías de participación comunitaria. \\
\hline Recreación ambiental. & Fomenta la relación de la persona y el medio ambiente en forma armónica. \\
\hline Recreación terapéutica. & Medio de apoyo a los procesos de rehabilitación física, social o psíquica. \\
\hline Recreación turística. & $\begin{array}{l}\text { Actividades de turismo organizado como excursiones guiadas o } \\
\text { actividades organizadas por las personas como paseos, viajes, } \\
\text { campamentos. }\end{array}$ \\
\hline & políticas de bienestar de las empresas para los empleados. \\
\hline Recreación deportiva. & $\begin{array}{l}\text { ncaminadas al mantenimiento físico, } \\
\text { l. }\end{array}$ \\
\hline Recreación pedagógica. & $\begin{array}{l}\text { Procesos de enseñanza-aprendizaje como metodología y complemento } \\
\text { liberador y globalizador. }\end{array}$ \\
\hline $\begin{array}{l}\text { Recreación artística y } \\
\text { cultural. }\end{array}$ & $\begin{array}{l}\text { Actividades sociales, culturales y artísticas que representan múltiples } \\
\text { formas de expresión del ser humano. }\end{array}$ \\
\hline
\end{tabular}

Fuente. Síntesis realizada por la autora a partir del Plan Nacional de Recreación 2004-2009.

Estos sectores nos permiten identificar como la recreación es todo un universo que abarca diferentes prácticas, argumento que nos presenta cómo el deporte es sólo una parte de éste universo, metafóricamente hablando, diríamos que el deporte es la vía láctea en medio de todo el universo, aspecto que se debe tener en cuenta en el momento de diseñar un programa de recreación para niños y niñas desde un proceso riguroso de participación infantil, donde sean los actores implicados, los que definan sus representaciones de recreación y de allí las actividades que los recrean.

Al poner en diálogo estas dos perspectivas podemos comprender cómo la recreación además de ser un derecho es un proceso de acción participativa que facilita comprender 
la vida como una experiencia de felicidad, goce, creación y libertad, siendo ésta un proceso dinámico y transformador que conlleva al pleno desarrollo de las potencialidades y dimensiones de la persona; significado que resalta su papel protagónico como un proceso que conlleva al desarrollo humano integral.

Finalmente este diálogo nos invita a comprender la recreación más allá de una ley positiva que se define por medio de la norma para dar paso a la comprensión de la ley natural, como nos invitan los postulados aristotélicos, para comprender la recreación y su relación íntima y creadora con la persona, lo que llevaría a un estado de felicidad, estado, que bien es cierto, es una categoría filosófica, la cual no es pertinente desarrollar desde los temas que convocaron esta investigación; sin embargo, es importante mencionarla para resaltar el papel que la recreación tiene en el desarrollo humano integral de la persona, el cual supone ir más allá de la satisfacción de necesidades básicas, para buscar la plenitud del ser, afirmación que nos puede cuestionar respecto a ¿cómo en la sociedad actual, con los niveles crecientes de pobreza y desigualdad que existen, es posible hablar de ir más allá de satisfacer las necesidades básicas, para pasar a un plano en el que todos y todas tengan la oportunidad de potencializar sus diferentes dimensiones como personas? En este panorama toma importancia reconocer:

\section{¿Cuál es la relación de la recreación con el desarrollo humano integral?}

Ahondemos entonces en la relación que tiene la recreación con el desarrollo humano integral, iniciando con la definición de desarrollo humano para comprender más adelante el concepto de desarrollo humano integral.

Si iniciamos el recorrido por la historia de la humanidad, descubrimos la manera en la que el desarrollo ha sido un proceso innato, desde lo que implica una evolución biológica y psicológica de la persona que pasa por las diferentes etapas de la vida.

El concepto de desarrollo humano surge de la dinámica natural de la vida de las comunidades humanas con el fin de nivelar armónicamente sus necesidades dirigidas a 
aprovechar las ventajas que les proporciona el entorno frente a la satisfacción de bienes, el acceso a los derechos, la oferta de servicios y la consiguiente garantía de recursos para su autosostenimiento, luego de haber adoptado un discurso de progreso y crecimiento económico que ha traído un impacto ambiental y social negativo, marcadas desigualdades y pobreza; como lo expresa Escobar:

Basta una mirada superficial a los paisajes biofísicos, económicos y culturales de la mayor parte del Tercer Mundo para darse cuenta de que el desarrollo está en crisis, y que la violencia, pobreza y deterioro social y ambiental crecientes son el resultado de cincuenta años de recetas de crecimiento económico, "ajustes estructurales", macro proyectos sin evaluación de impacto, endeudamiento perpetuo y marginamiento de la mayoría de la población de los procesos de pensamiento y decisión sobre la práctica social (Escobar, 2006, p. 11-12).

Este panorama mundial ha motivado diferentes alternativas del desarrollo como: la perspectiva de desarrollo y libertad de Sen, el desarrollo sostenible concebido por la ONU en el informe Bruntland: Our Comun Future, el desarrollo humano propuesto en el PNUD, el desarrollo a escala humana de Max-Neef o el postdesarrollo planteado por Arturo Escobar y Gustavo Esteva; alternativas que nos dan claves para fungir de nuevo al hombre en el corazón del desarrollo, de las políticas globales y locales y de las estrategias mundiales, puesto que como lo menciona Max-Neef: "este mundo quizás necesite algo sumamente simple que seamos; pero cuando digo ser, no me refiero a ser esto o aquello. Es, en mi opinión, el cambio personal más grande al que nos enfrentamos: ser lo suficientemente valientes para ser" (Max-Neef, 1993, p. 145). Y es que en el "ser", no el deber o en el tener, es que podemos reubicar al hombre en el corazón del desarrollo.

Ahora bien, luego de ubicar en el anterior recorrido histórico al desarrollo humano, a continuación profundicemos en él: 
El Programa de Naciones Unidas para el Desarrollo (PNUD), incorporó la categoría de desarrollo humano y ésta se ha usado en varios planteamientos de Política Pública, desde la siguiente definición:

Un proceso mediante el cual se busca la ampliación de las oportunidades para las personas, aumentando sus derechos y sus capacidades. Este proceso incluye varios aspectos de la interacción humana como la participación, la equidad de género, la seguridad, la sostenibilidad, las garantías de los derechos humanos y otros que son reconocidos por la gente como necesarias para ser creativos y vivir en paz (Naciones Unidas, 2008).

Como concepto abarca múltiples factores que se extienden desde la libertad política, económica o social hasta la satisfacción de estándares mínimos de dignidad con especial acento en la realización de los propios anhelos.

Conozcamos el planteamiento de la perspectiva que propone el desarrollo humano integral, la cual configura un mundo donde "todas las personas tienen la capacidad de desarrollar todo su potencial, satisfaciendo sus necesidades físicas básicas de manera sostenible, mientras viven con dignidad en una sociedad justa y pacífica. Se basa en relaciones correctas” (Burpee, Heinrich \& Zemanek, 2008, p. 2).

Los tres elementos clave del desarrollo humano integral son:

Tabla 2

Elementos del desarrollo humano integral.

\begin{tabular}{ll}
\hline Elemento. & Implicaciones. \\
\hline Holístico. & $\begin{array}{l}\text { El desarrollo humano integral promueve el bienestar de cada persona y de todas } \\
\text { las personas, en todos los aspectos de su vida, es decir, a nivel económico, social, } \\
\text { político, cultural, ecológico y espiritual. }\end{array}$ \\
\hline Solidaridad. & $\begin{array}{l}\text { El desarrollo humano integral promueve los derechos y responsabilidades de } \\
\text { cada persona y de todas las personas entre sí. }\end{array}$ \\
\hline Justicia y Paz. & $\begin{array}{l}\text { El desarrollo humano integral promueve una sociedad justa y pacífica que } \\
\text { respeta la dignidad de todas las personas. }\end{array}$ \\
\hline
\end{tabular}

Fuente. Síntesis realizada por la autora a partir de los postulados de Burpee, Heinrich \& Zemanek, 2008. 
Al identificar dichos elementos que caracterizan al desarrollo humano integral, podemos analizar como éste hace referencia no sólo al desarrollo de la persona sino a su relación con el otro y la construcción del tejido social.

Reflexionemos con la siguiente frase de Dupré en torno al concepto de desarrollo humano integral en la infancia: "el niño, la afectividad, la inteligencia y el movimiento constituyen un todo indisoluble" (citado en Perinat, 2000, p. 97). Para hablar de desarrollo humano integral debemos comprender que el ser humano "no es un agregado de elementos yuxtapuestos; es un todo integrado que constituye un suprasistema dinámico, formado por muchos subsistemas perfectamente coordinados: el subsistema físico, el químico, el biológico, el psicológico, el social, el cultural, el ético-moral y el espiritual” (Martínez, 2009, p. 119-120).

Al comprender la persona como una unidad indisoluble, desde una perspectiva holística del ser, podemos identificar las siguientes dimensiones del desarrollo humano integral:

Tabla 3

Dimensiones del desarrollo humano integral.

\begin{tabular}{|c|c|}
\hline Dimensión. & Definición. \\
\hline Desarrollo neurofisiológico. & $\begin{array}{l}\text { Hace referencia a la dimensión biológica. Afirma Perinat "el } \\
\text { desarrollo es metamorfosis, o sea, cambios en la estructura } \\
\text { orgánica y subsiguientemente en sus funciones } \\
\text { (comportamiento)". (Perinat, 2003, p.42) }\end{array}$ \\
\hline $\begin{array}{l}\text { Desarrollo cognitivo, inteligencia y } \\
\text { creatividad. }\end{array}$ & $\begin{array}{l}\text { "El desarrollo cognoscitivo comprende una interiorización } \\
\text { progresiva de formas lógicas que se manifiestan, primeramente, a } \\
\text { través de la acción motriz y posteriormente por una total } \\
\text { representación simbólica" (Muñoz, 2003, p.31) }\end{array}$ \\
\hline $\begin{array}{l}\text { Desarrollo psicológico, afectivo, } \\
\text { social y cultural. }\end{array}$ & $\begin{array}{l}\text { Perinat afirma como "la dimensión psicológica y específicamente } \\
\text { humana, se lleva a cabo en el seno de la relación social." (Perinat, } \\
\text { 2003, p. } 46 \text {.) }\end{array}$ \\
\hline $\begin{array}{l}\text { Desarrollo moral, ético y de } \\
\text { valores. }\end{array}$ & $\begin{array}{l}\text { Hace referencia a la dimensión axiológica de la persona, donde } \\
\text { los principios y valores entran en la relación de sí misma, el otro } \\
\text { y el entorno. }\end{array}$ \\
\hline
\end{tabular}

Fuente. Recopilación realizada por la autora a partir de las fuentes citadas. 
Afirma Osorio "asumir a la recreación como mediadora de procesos de desarrollo humano, significa comprenderla desde sus beneficios en cada una de las dimensiones de desarrollo de los seres humanos y tener claridad sobre las condiciones que hacen estos beneficios posibles" (Osorio, 2005, s/p). Entonces, para que la recreación garantice su relación con el desarrollo humano "requiere de unas condiciones éticas, políticas, de empoderamiento individual y colectivo, de desarrollo del conocimiento que hagan de los espacios humanos, ambientes para el desarrollo humano con impacto sobre los niveles y condiciones de vida de las personas" (Osorio, 2005, s/p).

En esta comprensión del desarrollo humano integral, donde la persona es una unidad, mas no fragmentos de partes, es donde la recreación, con su perspectiva holística que le habla directamente a la esencia del ser, imprime una fuerza a su papel como medio que potencializa el desarrollo humano integral y la construcción de tejido social.

\section{La participación infantil.}

En consonancia con el Artículo 1 de la Constitución Política de la República de Colombia:

Colombia es un Estado social de derecho, organizado en forma de República unitaria, descentralizada, con autonomía de sus entidades territoriales, democrática, participativa y pluralista, fundada en el respeto de la dignidad humana, en el trabajo y la solidaridad de las personas que la integran y en la prevalencia del interés general (Constitución Política de la República de Colombia, 1991, s/p).

Queremos ahondar en el rol de los niños y niñas en nuestro país como ciudadanos de derechos, quienes, al estar en una nación democrática y participativa, tienen derecho a expresarse libremente respecto a los aspectos públicos que los convocan, como es el caso de su derecho a la recreación, el cual para ellos, y en el caso de los infantes colombianos, como lo concluye la investigación del Derechómetro, es uno de los más importantes: "los 
derechos más identificados por los niños y las niñas se encontraron los de tener una familia, el juego y la recreación” (ICBF\&FUNLIBRE, 2003, s/p).

La participación es: "un proceso social que resulta de la acción intencionada de individuos y grupos en busca de metas específicas, en función de intereses diversos y en el contexto de tramas concretas de relaciones sociales y de poder" (Velásquez \& González, 2000, p. 19). Es importante subrayar que "la participación social es un derecho humano esencial de toda persona, y una sociedad puede considerarse democrática cuando todos sus ciudadanos y ciudadanas participan. La participación es uno de los componentes más importantes de la construcción de la democracia y, a través de ella, se contribuye a asegurar el cumplimiento de otros derechos" (Apud, s/f, p. 4). Y si los niños y niñas son ciudadanos, actores de sus derechos, podemos resaltar la importancia que tiene la participación infantil en el diseño y formulación de políticas públicas en Colombia.

Para comprender la participación infantil, es fundamental preguntarse sobre el significado de participar, lo cual puede ser "hacer acto de presencia, tomar decisiones, estar informado de algo, opinar, gestionar o ejecutar; desde estar simplemente apuntado a, o ser miembro de, a implicarse en algo en cuerpo y alma" (Trilla \& Novella, 2005, p. 141). Dicha definición nos permite comprender como el proceso de participación puede darse en diferentes niveles:

En algunos casos se trata de obtener información sobre un tema o decisión específica o emitir una opinión sobre una situación. En otros participar significa tener iniciativas que contribuyan a la solución de un problema. $\mathrm{O}$ bien puede tener un alcance mayor cuando se trata de procesos de concertación y negociación o de fiscalizar el cumplimiento de acuerdos y decisiones previas. En fin, la participación se reivindica como medio para la formulación, discusión y adopción de los grandes consensos sobre el desarrollo y la convivencia en el territorio (Velásquez \& González, 2000, p. 20). 
Ahora bien, ¿qué supone la participación infantil? Apud nos presenta la respuesta a éste interrogante.

La participación infantil supone colaborar, aportar y cooperar para el progreso común, así como generar en los niños, niñas y jóvenes confianza en sí mismos y un principio de iniciativa. Además, la participación infantil ubica a los niños y niñas como sujetos sociales con la capacidad de expresar sus opiniones y decisiones en los asuntos que les competen directamente en la familia, la escuela y la sociedad en general. De igual forma, la participación infantil nunca debe concebirse como una simple participación de niños y jóvenes, sino como una participación en permanente relación con los adultos, y debe ser considerada como un proceso de aprendizaje mutuo tanto para los niños como para los adultos (Apud, s/f, p. 4).

Pasemos ahora al marco normativo que soporta el derecho a la participación infantil. La Convención sobre los Derechos del niño promulgada por la Asamblea General de las Naciones Unidas en 1989 es “el primer documento importante donde se reconoce de forma explícita y clara el protagonismo de la infancia y su capacidad de participar en la sociedad y de ejercer determinados derechos civiles y políticos" (Trilla \& Novella, 2005, p. 156).

A nivel nacional el Artículo 31 de la Ley 1098 de 2006 ordena:

El derecho a la participación de los niños, las niñas y los adolescentes. Para el ejercicio de los derechos y las libertades consagradas en este código los niños, las niñas y los adolescentes tienen derecho a participar en las actividades que se realicen en la familia, las instituciones educativas, las asociaciones, los programas estatales, departamentales, distritales y municipales que sean de su interés. El Estado y la sociedad propiciarán la participación activa en organismos públicos y privados que tengan a cargo la protección, cui dado y educación de la infancia y la adolescencia (2006). 
Y a nivel local, en Bogotá el decreto 520 de 2011 Por medio del cual se adopta la Política Pública de Infancia y Adolescencia de Bogotá, D. C. en su artículo 6 "Reconocer a los niños y las niñas desde la primera infancia hasta la adolescencia como ciudadanos, ciudadanas y sujetos activos titulares de derechos" (2011). Reconocimiento que se define en el eje $\mathrm{N}^{\circ} 1$ denominado Niños, niñas y adolescentes en ciudadanía plena, en el artículo 8. Dicho eje comprende los componentes y situaciones que se identifican como básicas para asegurar el ejercicio y disfrute de los derechos de los niños y las niñas desde la primera infancia hasta la adolescencia en Bogotá. Parte del concepto de protección integral de los niños y las niñas en todas las etapas de su ciclo vital para el reconocimiento de ellos y ellas como sujetos activos en capacidad de aportar al desarrollo social y titulares de derechos, la garantía como cumplimiento de los mismos, la prevención de su amenaza o vulneración y la seguridad de su restablecimiento inmediato. Soporte legal que resalta una vez más la importancia de la participación infantil.

Pero ¿cómo hacer realidad la participación infantil?, ¿qué órganos promueven dicha participación?, ¿qué metodologías se podrían emplear o se han empleado para propiciar espacios de participación?, como lo presenta el Comité Operativo Distrital de Infancia y Adolescencia:

Los niños y las niñas durante la primera infancia requieren de mecanismos especiales para ejercer sus derechos de opinión, expresión, pensamiento y asociación frente a las decisiones que toma la sociedad y que les afectan; sin embargo, no se cuenta con información que permita dar cuenta del estado de realización del derecho a la participación para la primera infancia (CODIA, 2011, p. 52).

Sin embargo, podemos identificar estrategias para hacer realidad la participación infantil. Por ejemplo a nivel local encontramos la experiencia del Gobierno de Bogotá Humana en el 2012, al crear el Consejo Consultivo Distrital de niños, niñas y adolescentes y los Consejos Locales de niños, niñas y adolescentes, como lo ordena el Decreto 121 de 
2012 en el Artículo 1 ${ }^{\text {o }}$ "Creación del Consejo Consultivo Distrital de Niños, Niñas y Adolescentes y Consejos Locales de Niños, Niñas y Adolescentes. Créase el Consejo Consultivo Distrital de niños, niñas y adolescentes y los Consejos Locales de niños, niñas y adolescentes, como espacios de participación, análisis y discusión de las temáticas de la ciudad, en especial aquellas que les conciernen a los niños, niñas y adolescentes y que garantizan el ejercicio pleno de sus derechos y libertades" (2012).

Respecto a los Consejos de niños y niñas CODIA resalta que "esta instancia busca ser el mecanismo mediante el cual se tenga en cuenta la voz de los niños y las niñas en la toma de decisiones de política pública" (CODIA, 2011, p. 52). Experiencia, que sin duda, es un primer paso para hacer realidad la participación infantil.

Otros mecanismos de participación infantil, además de los consejos locales o el consejo consultivo distrital de niños, niñas y adolescentes, es el gobierno escolar, una instancia que desde tempranas edades desarrolla en los niños y niñas actitudes de participación en la toma de decisiones de sus instituciones educativas, se podría pensar la escuela como su pequeña Polis y los roles del gobierno escolar como el ejercicio de participación que los niños y niñas pueden ejercer. En éste aspecto es importante dejar abierta la reflexión, respecto a ¿qué tan consientes se desarrollan éstos procesos en las instituciones educativas para formar desde temprana edad el gusto por participar de las decisiones que implican la construcción de un bien común?

¿Qué se entiende por Política Pública y a qué hace referencia la fase de diseño y formulación?

Para resaltar el papel de la participación en el diseño y formulación de las políticas públicas, revisemos el concepto de política pública para comprender su relación e importancia: "Las políticas son el diseño de una acción colectiva intencional" (Aguilar \& Lima, 2009, p. 2). Las políticas públicas son acciones que dan solución a un problema, una necesidad o una intención común, priorizando, definiendo alternativas y determinando 
objetivos; proceso que genera tensiones de los diferentes actores sociales. Según Aguilar son "decisiones de gobierno que incorporan la opinión, la participación, la corresponsabilidad y el dinero de los privados, en su calidad de ciudadanos electores y contribuyentes" (Aguilar, 1992, p.36).

De acuerdo a la literatura que propone el diseño y formulación de las políticas públicas, dicho proceso se sintetiza en las fases que responden a un proceso de planeación participativa que genera factibilidad, puesto que surge de una problemática real y de alto impacto que requiere una intervención urgente por medio de la acción que constituye una política pública, la cual se entiende como una fuerza de transformación social hacia el desarrollo de la comunidad. En consecuencia a este proceso de planeación los pasos generales que responden al diseño y formulación de una política pública son:

Realidad social: Lectura de contexto previo al diseño, el cual se debe sustentar en conexión con realidad. La definición del problema debe estar en armonía con lo que percibe y requiere la sociedad. Barra cita a Meltsner, quien nos sugiere que:

La ausencia de investigación sobre factibilidad política no había proliferado por la ausencia de metodologías adecuadas, puesto que la tradición sobre el análisis de políticas desde los cuarenta hacia adelante había caracterizado el estudio de las políticas públicas con los métodos racionalistas eminentemente econométricos y cuantitativos. Asevera, que es labor del especialista en Políticas Públicas realizar el diagnóstico sobre el ecosistema político (Barra, s/f, p. 110).

Ecosistema político que hace referencia al contexto social, a las realidades, necesidades, problemáticas, prioridades, preferencias, de las comunidades,

Intervención de actores sociales. Quienes intervienen en la territorialización de la Política Pública; se realiza un proceso de análisis y participación de los diferentes actores sociales, quienes finalmente son los que permiten que la política se realice. Con los actores sociales se lograrán los consensos sociales, “de esa forma se evitara la multiplicidad de 
definiciones sobre lo que es un problema público, y así encuadrar las elecciones de políticas públicas de acuerdo a una concepción común de la realidad” (Barra, s/f, p. 112). Este proceso permite generar un equilibrio entre dos extremos, como lo cita Barra: "no darle importancia a lo que la ciudadanía define como problema, y lo segundo, la tendencia a sobredimensionar los que los especialistas definen como problema" (Barra, s/f, p. 112), puesto que muchas veces los "especialistas" que diseñan las políticas públicas lo realizan, algunas veces de forma centralizada, desde la comprensión de la realidad regional y local que ellos creen más no desde un diagnóstico y una formulación que surja del diálogo con las comunidades. Por tal motivo, este aspecto es fundamental para hablar de factibilidad, puesto que para que sean realizables, deben ser pertinentes y sentidas por quienes finalmente ponen en marcha el accionar de la política pública quienes son los actores que intervienen en la problemática, y cuya transformación es el objeto de la política pública.

Evaluación ex-ante, mediante, o ex-post: La política pública no puede ser entendida como una verdad absoluta, debe tener un proceso de evaluación que permita controlar y garantizar si ha logrado los objetivos para los cuales fue formulada, los fines para los cuales ha sido diseñada, proceso que define si la política pública se puede promover a otro periodo, se modifica, o en definitiva se cambia. Ahora buen si las políticas son diseños para la acción pública “estos diseños deben luego ser implementados, evaluados y, de ser necesario, corregidos. Un proceso -o ciclo- de políticas públicas tan ideal, de "planificarhacer-verificar- actuar" está, por supuesto, sujeto a fuertes influencias políticas, algunas buenas, otras malas" (Banco Mundial, 2010, p. 4).

Este proceso de planeación de la política pública debe permitir que ésta no este ceñida a un periodo de tiempo de un gobernante, sino que responda a una problemática sentida y prioritaria de la sociedad, lo cual las hará factibles. Es por tal motivo que "la fase de construcción (diseño y formulación) de políticas, que a juicio de los autores, es la etapa más compleja del ciclo de políticas donde convergen la dimensión técnica y la política" (Santibáñez, Barra \& Ortiz; 2006 citado por Barra, p. 128). 


\section{¿Cuál es la importancia de la participación en la fase de diseño y formulación de la Política Pública?}

Al comprender como el proceso de construcción de las políticas públicas, no se debe limitar únicamente al gobierno, sino que es un proceso que surge del diálogo de las comunidades, quienes son la fuente primaria para identificar las necesidades y problemáticas, podemos resaltar el papel de la participación en la fase de diseño y formulación de la política pública.

La participación puede asumir un papel determinante en la orientación de las políticas públicas y en la transformación de las relaciones entre la ciudadanía y el gobierno local. Esa posibilidad depende, sin embargo, de, por lo menos, dos condiciones: de una parte, una decidida voluntad de los gobiernos (nacional, regionales y municipales) de crear las oportunidades para el ejercicio de la participación. De otra, la existencia de ciudadanos y ciudadanas, de organizaciones sociales y de agentes participativos que hagan uso de esas oportunidades y las traduzcan en acciones encaminadas a democratizar y cualificar los resultados de la gestión pública (Velásquez \& González, 2000, p. 20).

Es una apuesta por las múltiples formas de coordinación de las intervenciones públicas donde los diferentes actores sociales generen sinergia en un proceso político y técnico para el diseño y formulación de las políticas públicas.

Finalmente es de gran valor para esta investigación resaltar el aporte del concepto de participación infantil en una nación democrática, puesto que la construcción de un bien común se realiza con todos los ciudadanos, y si los niños y niñas son ciudadanos y actores para quienes priman sus derechos, como lo veremos en el marco normativo que sustenta éste derecho a continuación, en la interacción de los adultos y los niños de seguro se generaran aprendizajes mutuos e insumos importantes para el diseño, formulación e implementación de políticas públicas que los convoquen, puesto que sus voces, al ser escuchadas, expresaran necesidades, intereses, gustos, preferencias, representaciones, 
incluso ideas con un alto potencial de innovación, aspecto que se resalta por la característica de creatividad y capacidad de soñar que tienen los niños, elementos que sin duda pueden y deben influir en la toma de decisiones de los gobernantes y técnicos para diseñar las políticas y programas que busquen transformar y mejorar sus realidades.

Expresa Tonucii "El niño se considera un indicador ambiental sensible: si en una ciudad se ven niños que juegan y pasean solos, significa que la ciudad está sana; si no es así, es que la ciudad está enferma" (Tonucci, 2006, p. 3). Lo mismo podría transpolarse al concepto de democracia, en este sentido, la participación infantil es un indicador que nos puede decir si nuestra nación realmente es una república democrática, participativa y pluralista, puesto que aunque los niños y niñas no sean considerados ciudadanos por la Ley colombiana, desde que una persona nace hace parte de la población que conforma nuestra nación y desde postulados más filosóficos como los de Adela Cortina, los niños y niñas harían parte de una ciudadanía cosmopolita.

A continuación se presenta la síntesis de los conceptos abordados.

Tabla 4

Matriz síntesis de los conceptos y características de la recreación, el desarrollo humano integral, la participación infantil y el diseño y formulación de Políticas Públicas.

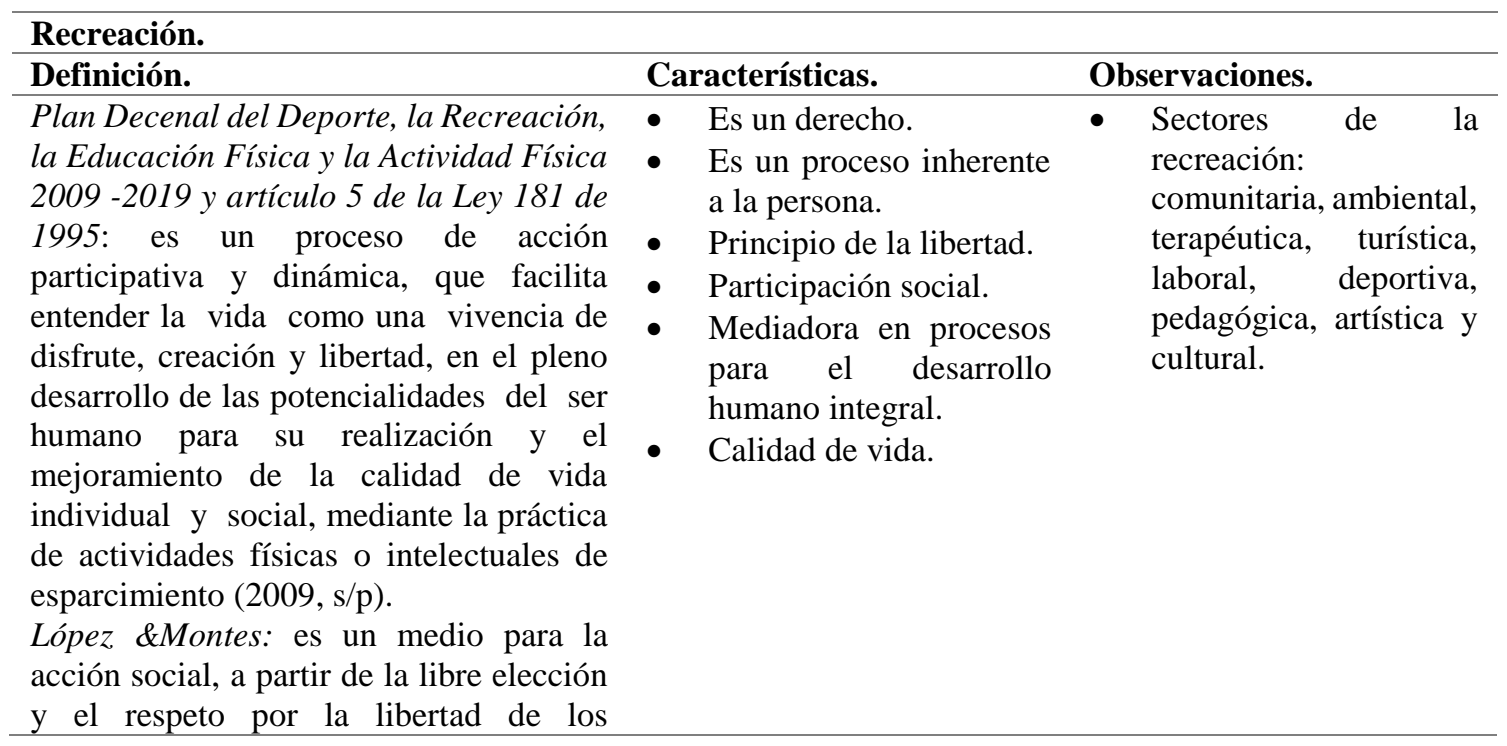


individuos que conforman una sociedad. De esta manera es mediadora de los procesos de desarrollo humano, donde lo esencial es la comprensión de la realidad del ser humano actual, posibilitando espacios de diversión, de descanso, de participación social, de expresión y socialización de toda su realidad en la perspectiva de ser propiciadora del desarrollo integral (2008, p. 23).

\section{Desarrollo humano integral.}

\section{Definición.}

Programa de Naciones Unidas para el Desarrollo (PNUD): Define Desarrollo Humano como un proceso mediante el cual se busca la ampliación de las oportunidades para las personas, aumentando sus derechos y sus capacidades. Este proceso incluye varios aspectos de la interacción humana como la participación, la equidad de género, la seguridad, la sostenibilidad, las garantías de los derechos humanos y otros que son reconocidos por la gente como necesarias para ser creativos y vivir en paz (2008, $\mathrm{s} / \mathrm{p})$.

Burpee, Heinrich \& Zemanek: Definen Desarrollo Humano Integral como el concepto que configura un mundo donde todas las personas tienen la capacidad de desarrollar todo su potencial, satisfaciendo sus necesidades físicas básicas de manera sostenible, mientras viven con dignidad en una sociedad justa y pacífica. Se basa en "relaciones correctas" (2008, s/p).

\section{Participación infantil.}

\section{Definición.}

Trilla \& Novella: Es un derecho jurídicamente establecido; por otra parte, sirve para mejorar el funcionamiento de los ámbitos en los que se produce; $y$, por último, constituye un excelente medio (por no decir el mejor) para la formación de la ciudadanía en los valores democráticos $(2011, \mathrm{~s} / \mathrm{p})$

Participar puede significar hacer acto de presencia, tomar decisiones, estar informado de algo, opinar, gestionar o ejecutar; desde estar simplemente apuntado a, o ser miembro de, a

\section{Características.}

- Es un proceso.

- Holístico: promueve el bienestar de cada persona y de todas las personas, en todos los aspectos de su vida, es decir, a nivel económico, social, político, cultural, ecológico y espiritual. También promueve la integridad de la creación.

- Solidaridad: promueve los derechos y responsabilidades de cada persona y de todas las personas entre sí.

- Justicia y Paz: promueve una sociedad justa y pacífica que respeta la dignidad de todas las personas.

\section{Observaciones.}

- Dimensiones del Desarrollo Humano Integral: neurofisiológico, cognitivo, inteligencia $\mathrm{y}$ creatividad, psicológico, afectivo, social y cultural, moral, ético y de valores.

\section{Características.}

- Es un derecho.

- Permite formación en valores democráticos.

- Permite aprendizajes mutuos entre niños $\mathrm{y}$ adultos.

- Potencial creativo de los niños y niñas.

\section{Observaciones.}

- Los niños son ciudadanos, en consecuencia la participación es un derecho.

- Experiencia de los consejos infantiles municipales como órganos de participación social y medios para la formación de la ciudadanía. 
implicarse en algo en cuerpo y alma (2005, s/p)

Apud: La participación infantil supone "colaborar, aportar y cooperar para el progreso común", así como generar en los niños, niñas y jóvenes confianza en sí mismos y un principio de iniciativa. Además, la participación infantil ubica a los niños y niñas como sujetos sociales con la capacidad de expresar sus opiniones y decisiones en los asuntos que les competen directamente en la familia, la escuela y la sociedad en general. De igual forma, la participación infantil nunca debe concebirse como una simple participación de niños y jóvenes, sino como una participación en permanente relación con los adultos, y debe ser considerada como un proceso de aprendizaje mutuo tanto para los niños como para los adultos. (s/f)

\section{Políticas Públicas}

Definición.

"Las políticas son el diseño de una acción colectiva intencional; el curso que toma la acción como resultado de las decisiones e interacciones que comporta son los hechos reales que la acción produce" (Aguilar \& Lima, 2009, p. 2).

"Decisiones de gobierno que incorporan la opinión, la participación, la corresponsabilidad y el dinero de los privados, en su calidad de ciudadanos electores y contribuyentes" (Aguilar, 1992, p.36).

\section{Características.}

- Acción que propone la solución a una problemática, necesidad o interés común.

- Presenta tensiones e intenciones de los actores sociales.

- Participación de diversos actores sociales.

\section{Observaciones.}

- Fases del ciclo de la política pública: agenda, diseño y formulación, implementación y evaluación.

- Enfoques de diseño formulación: De abajo hacia arriba (bottom-up) De arriba hacia abajo (top-down).

Fuente. Matriz elaborada por la autora a partir de las fuentes citadas.

Esta revisión conceptual, normativa y contextual nos invita a repensar el imaginario de la recreación, a comprender el desarrollo humano integral como un proceso que permite tanto a la persona como a la sociedad potencializar sus capacidades para alcanzar la plenitud y a descubrir el valor que en éstos procesos tiene la participación infantil como vehículo para hacer realidad la construcción de un mundo diferente y así como el potencial creativo de los niños y niñas los lleva a imaginar diferentes realidades, este recorrido nos deja el reto de crear metodologías que permitan una participación infantil efectiva, que podamos innovar en estrategias que permitan escuchar las voces de nuestros niños y niñas 
en los temas que los convocan, en los temas que son importantes para ellos, para diseñar políticas y programas que respondan a sus necesidades y a la satisfacción de sus derechos, como lo es el derecho de la recreación. Nos deja el reto de repensar la participación infantil desde la recreación, desde la construcción de metodologías que se apoyen del lenguaje universal de los niños y niñas: el juego.

\section{Diseño metodológico.}

\section{La presente Figura 2. Territorio donde se desarrolló la investigación.}

investigación se estructuró

a partir de un enfoque cualitativo, puesto que responde a un paradigma hermenéutico y se enmarca en las Ciencias Sociales y Humanas; de tipo descriptivo, en tanto, caracteriza a los niños y niñas beneficiarios de la Ludoteca del barrio Uval frente a sus preferencias, necesidades y prácticas recreativas.

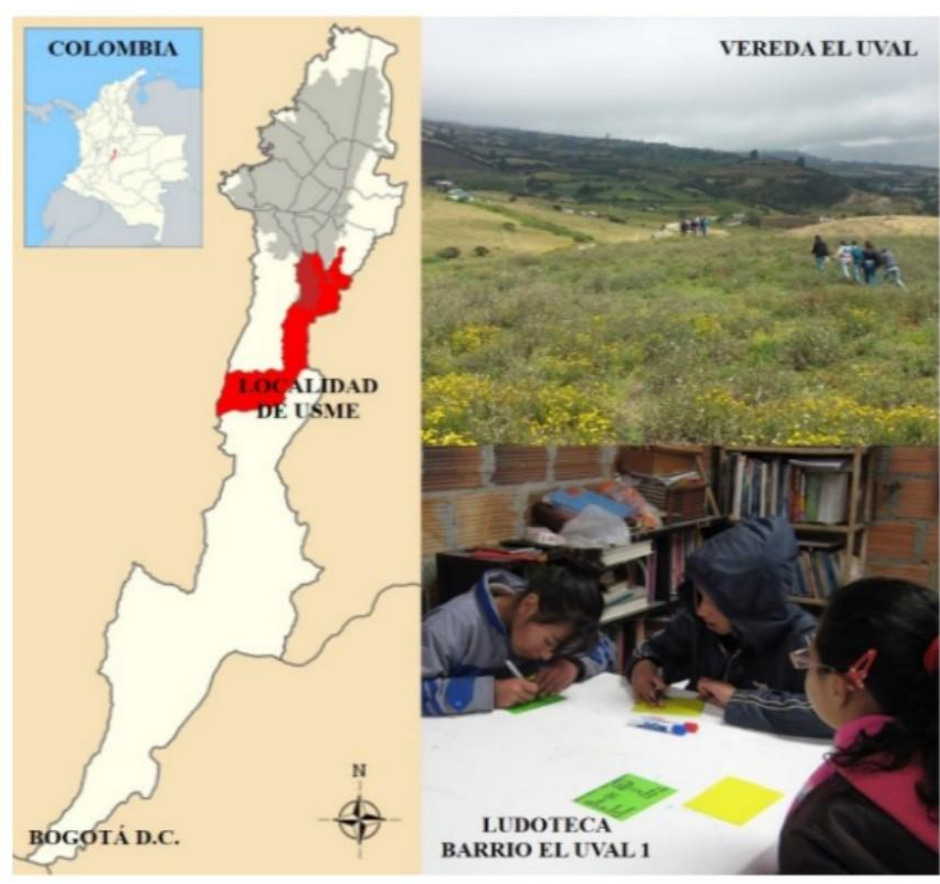

Fuente. Diseño realizado por la autora a partir de fotografias tomadas en las salidas de campo y del mapa de la localidad creado por Shadowxfox.

El territorio donde se realizó la investigación fue en la Ludoteca del barrio Uval perteneciente al Centro de Proyección Social Monte de Galilea, ubicado en la ciudad de Bogotá en la localidad de Usme ${ }^{10}$. La elección de la Ludoteca toma importancia al

\footnotetext{
${ }^{10}$ La localidad de Usme se ubica al sur de Bogotá, limita al occidente con la localidad de Ciudad Bolívar y el municipio de Pasca; al sur con la localidad de Sumapaz; al norte con las localidades de Tunjuelito, Rafael Uribe Uribe y San Cristóbal y al oriente con los municipios de Ubaque y Chipaque. Usme tiene una extensión total de 21.507 hectáreas (ha), de las cuales 3.029 se clasifican en suelo urbano y 18.477 se
} 
ser Proyección Social una función sustantiva de la Universidad Santo Tomás desde su estrategia de desarrollo comunitario, sustentada en su carácter humanista, lo cual imprime un sello característico como futura magíster tomasina en Planeación para el desarrollo.

Las etapas de la investigación desarrollaron los siguientes pasos, de los cuales, el proceso investigativo socializado en este artículo se presenta hasta la tercera etapa.

Figura 3. Etapas de la investigación.

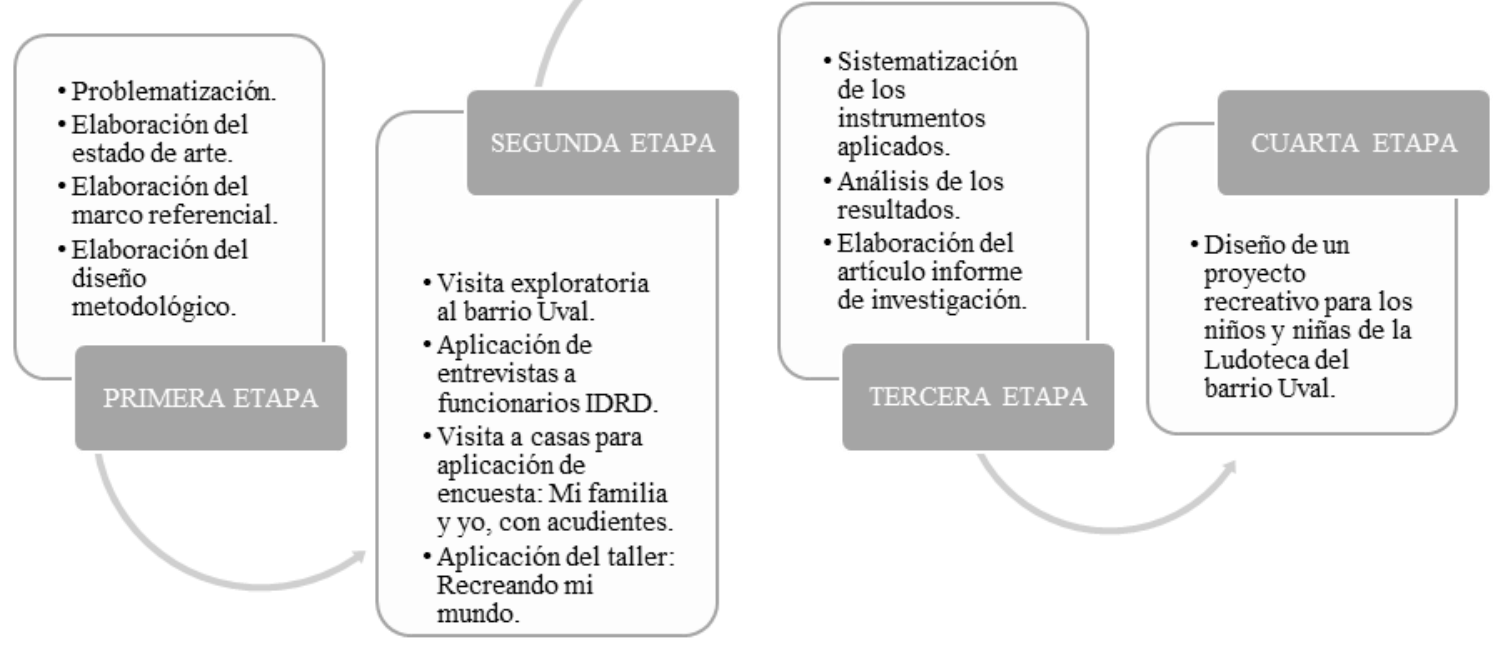

Fuente. Diseño realizado por la autora.

El objetivo general que orientó la investigación se centró en analizar las prácticas, preferencias y necesidades recreativas que los niños y niñas beneficiarios de la Ludoteca del barrio Uval manifiestan a través de un espacio de participación infantil como insumo para el diseño de un proyecto recreativo. Los Objetivos específicos fueron:

- Identifica las metodologías que se emplearon para incluir la voz de los niños y niñas en la formulación de la política pública de recreación para Bogotá 2009 2019 y de los programas recreativos de la localidad de Usme.

clasifican en suelo rural, lo que equivale al $85,9 \%$ del total de la superficie de la localidad. Usme es la segunda localidad con mayor extensión del Distrito. (Secretaría Distrital de Planeación, p. 11, 2009) 
- Caracterizar a los niños y niñas beneficiarios de la Ludoteca frente a sus prácticas y necesidades recreativas.

- Reconocer las preferencias recreativas de los niños y niñas de acuerdo a los sectores de la recreación.

Las técnicas empleadas para recolectar la información fueron: entrevista semiestructurada, donde se diseñó un instrumento con preguntas orientadoras y se aplicó a dos funcionarios del Instituto Distrital de Recreación y Deporte ${ }^{11}$ (IDRD), al jefe del área de Recreación el Lic. Oscar Ruiz ${ }^{12}$ y el coordinador local de Usme el Lic. Mario Salinas $^{13}$, funcionarios claves en el proceso de formulación de las políticas públicas distritales y programas locales en lo que refiere al derecho de la recreación. La segunda técnica empleada fue la encuesta, diseñando un instrumento denominado "Mi familia y yo", el cual se aplicó en una visita por las casas de los niños y niñas, a los acudientes. Y finalmente, un taller que empleó el juego ${ }^{14}$ como estrategia para vincular a la totalidad de niños y niñas beneficiarios de la Ludoteca del barrio Uval ente las edades de 6 a 12 años ${ }^{15}$, quienes fueron los sujetos principales de esta investigación; siendo 15 niños y niñas el total de la población en este estudio; cabe aclara que el universo de la población respondería al total de niños y niñas de la localidad de Usme, cifra que de acuerdo a la proyección para el año 2015 del DANE a partir del Censo General del año 2005 es de 126.355 para la población menor a 14 años.

${ }^{11}$ El Instituto Distrital de Recreación y Deporte (IDRD) es una entidad adscrita a la Secretaría de Cultura, Recreación y Deporte (SCRD), está dedicada a promover la recreación, el deporte, el buen uso de los parques y el aprovechamiento del tiempo libre.

${ }^{12}$ La sistematización de la entrevista se puede leer en https://goo.gl/PxssGt

${ }^{13}$ La sistematización de la entrevista se puede leer en https://goo.gl/HSPFJm

${ }^{14} \mathrm{El}$ juego es una actividad que "implica a la persona en su globalidad, proporcionándole medios para la expresión, la comunicación y el aprendizaje” (Omeñaca \& Ruiz, 2004, p. 9) y para los niños y las niñas es "necesario para el pleno desarrollo del cuerpo, el intelecto y la personalidad" (Pugmire-Stoy, 1996, p. 19)

${ }^{15}$ La edad de seis a doce años se elige de acuerdo con el planteamiento que realiza la Ley 1098 de 2006 respecto a las condiciones de ser niño, agrupando en dicho rango la etapa denominada infancia; por otra parte, dicha edad abarca el estadio operacional concreto propuesto por Jean Piaget, el cual contempla las edades de siete a doce años, donde "el niño es capaz de usar símbolos (representaciones mentales)... pueden razonar con lógica sobre las cosas y los acontecimientos que observan.” (El Sahili \& Munguía, 2011, p. 40) 
Figura 4. Técnicas e instrumentos ${ }^{16}$.
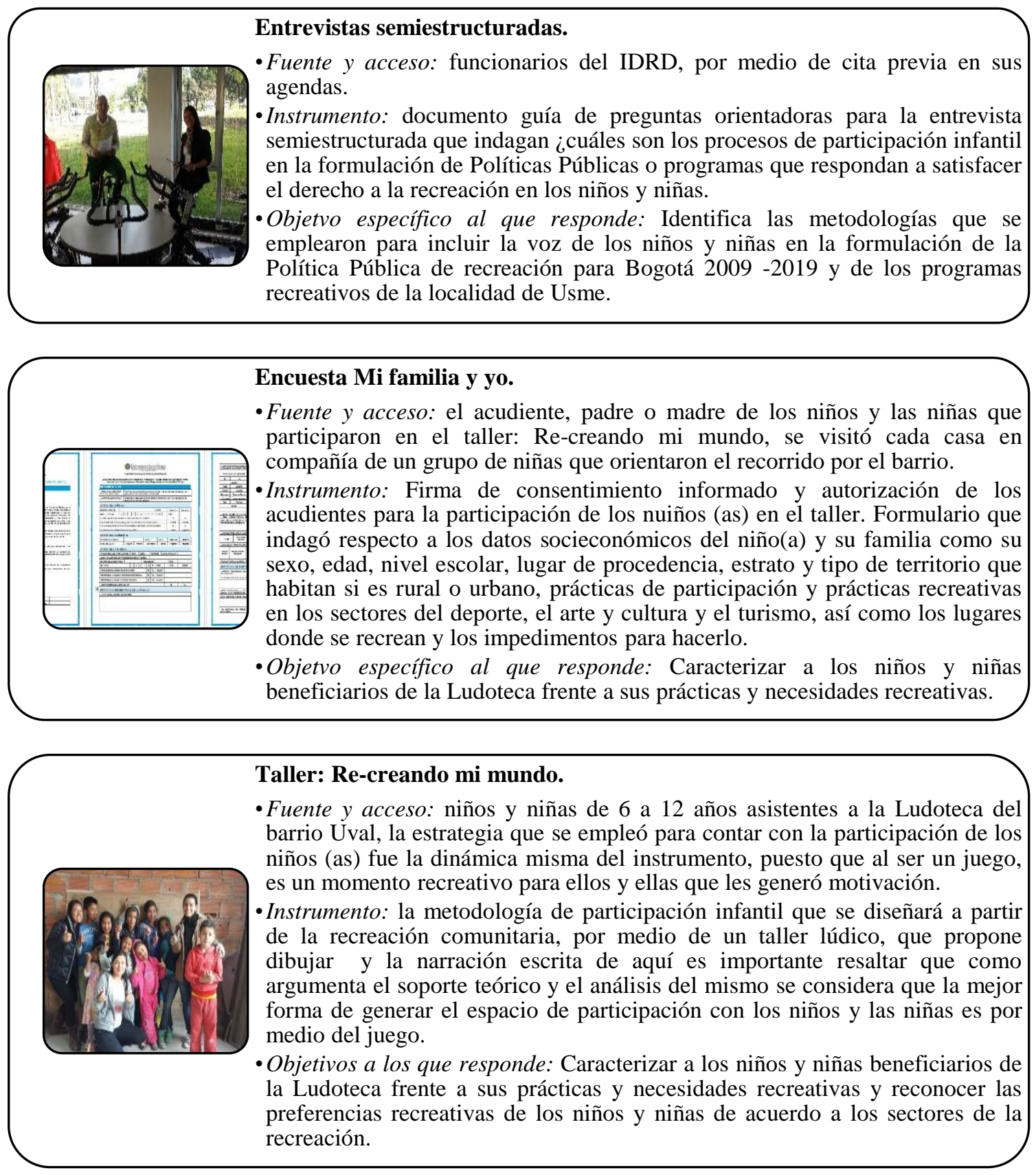

Fuente. La autora.

${ }^{16}$ Los instrumentos se pueden observar en https://goo.gl/YOgzKB 
La sistematización de los hallazgos se da por medio de una trascripción textual de las entrevistas semiestructuradas $\mathrm{y}$ diferentes matrices las cuales presentan una subcategorización para el análisis, estas fueron: las matrices en que se sistematizó las encuestas aplicadas ${ }^{17}$ que permitió la representación de dicha información en gráficas ${ }^{18}$, como parte del análisis estadístico y la matriz de taller ${ }^{19}$ donde se codificó los dibujos y escritos de cada niño y niña, lo que permitió conocer las ideas textuales expresadas por los sujetos.

En la segunda fase, se generaron dos matrices de análisis ${ }^{20}$ por sexo, por medio de la categorización de las prácticas recreativas por sectores: deportiva, artística cultural y otras, de acuerdo a las actividades mencionadas por los niños y niñas que más les gusta realizar y que les gustaría realizar para recrearse, además del grupo poblacional con quien le gustaría realizar la actividad que lo recrea, categorizando en familia, amigos y comunidad; finalmente se realiza una matriz donde se analizaron los lugares ${ }^{21}$ que plasmaron en la proyección de su territorio categorizando en escenarios urbanos, rurales y recreodeportivos; la última fase de éste análisis genera la síntesis que se ubica en la matriz de observables, ${ }^{22}$ para la elaboración de dicha matriz, se emplearon dos grandes categorías: recreación y participación infantil; sin embargo se consideró importante realizar una caracterización socioeconómica de la población de niños y niñas y sus familias como insumo para analizar sus prácticas, preferencias y necesidades recreativas.

Las técnicas empleadas para el análisis fueron la documental, estadística y de contenido. En la tabla 5 se presentan las categorías, los observables y el instrumento que permitió recolectar la información.

\footnotetext{
${ }^{17}$ La matriz de sistematización de la encuesta Mi familia y yo se puede observar en https://goo.gl/gHCf7w 18 El documento con las representaciones gráficas de la sistematización se puede observar en https://goo.gl/e7FBte

19 La matriz síntesis de sistematización del taller Re-creando mi mundo se puede observar en https://goo.gl/3r303z

20 Las matrices de análisis del taller Re-creando mi mundo según sexo se pueden observar en https://goo.gl/gjTUJK

${ }^{21}$ La Matriz de análisis del Taller Re-creando mi mundo lugares que incluiría en su mundo se puede observar en https://goo.gl/4zUxS9

${ }^{22}$ La matriz de categorías, observables, instrumentos y análisis se puede observar en https://goo.gl/mj5JcK
} 
Tabla 5

Categorías de análisis.

\begin{tabular}{|c|c|c|}
\hline Categoría. & Observables. & Instrumento. \\
\hline Socioeconómica. & $\begin{array}{l}\text { Características socioeconómicas de los } \\
\text { niños(as) y sus familias. }\end{array}$ & Encuesta: Mi familia y yo. \\
\hline \multirow[t]{9}{*}{ Recreación. } & \multirow[t]{2}{*}{ Concepto de recreación. } & Encuesta: Mi familia y yo. \\
\hline & & $\begin{array}{l}\text { Entrevista semiestructurada a } \\
\text { funcionarios del IDRD. }\end{array}$ \\
\hline & Prácticas recreativas de la familia. & Encuesta: Mi familia y yo. \\
\hline & Practicas recreativas de los niños y niñas. & Taller: Re-creando mi mundo \\
\hline & $\begin{array}{l}\text { Preferencias de las prácticas recreativas de los } \\
\text { niños y niñas. }\end{array}$ & Taller: Re-creando mi mundo \\
\hline & \multirow{2}{*}{$\begin{array}{l}\text { Escenarios para realizar las prácticas } \\
\text { recreativas. }\end{array}$} & Encuesta: Mi familia y yo. \\
\hline & & Taller: Re-creando mi mundo \\
\hline & Barreras para realizar prácticas recreativas. & Encuesta: Mi familia y yo. \\
\hline & $\begin{array}{l}\text { Importancia que la familia le da al derecho de } \\
\text { la Recreación. }\end{array}$ & Encuesta: Mi familia y yo. \\
\hline \multirow[t]{9}{*}{$\begin{array}{l}\text { Participación } \\
\text { Infantil. }\end{array}$} & $\begin{array}{l}\text { Participación de los niños(as) y sus familias } \\
\text { en programas de recreación que promueve la } \\
\text { alcaldía local. }\end{array}$ & Encuesta: Mi familia y yo. \\
\hline & $\begin{array}{l}\text { Participación de los miembros de la familia } \\
\text { en prácticas recreativas. }\end{array}$ & Encuesta: Mi familia y yo. \\
\hline & $\begin{array}{l}\text { Temas que incorporaría en una agenda local } \\
\text { en materia de recreación. }\end{array}$ & Encuesta: Mi familia y yo. \\
\hline & $\begin{array}{l}\text { Prácticas de participación ciudadana del } \\
\text { acudiente. }\end{array}$ & Encuesta: Mi familia y yo. \\
\hline & Prácticas de participación del niño(a). & Encuesta: Mi familia y yo. \\
\hline & Concepto de participación. & $\begin{array}{l}\text { Entrevista semiestructurada a } \\
\text { funcionarios del IDRD. }\end{array}$ \\
\hline & Concepto de participación infantil. & $\begin{array}{l}\text { Entrevista semiestructurada a } \\
\text { funcionarios del IDRD. }\end{array}$ \\
\hline & $\begin{array}{l}\text { Metodologías y/o experiencias de } \\
\text { participación infantil. }\end{array}$ & $\begin{array}{l}\text { Entrevista semiestructurada a } \\
\text { funcionarios del IDRD. }\end{array}$ \\
\hline & $\begin{array}{l}\text { Incorporación en la agenda pública de las } \\
\text { voces de los niños(as). }\end{array}$ & $\begin{array}{l}\text { Entrevista semiestructurada a } \\
\text { funcionarios del IDRD. }\end{array}$ \\
\hline
\end{tabular}

Fuente. La autora a partir de los instrumentos diseñados. 


\section{Resultados y recomendaciones.}

\section{Metodologías de participación infantil.}

Los resultados y las discusiones que se encontraron al hacer análisis de las entrevistas y la revisión documental de la metodología de participación empleada en el diseño y formulación de la Política Pública de recreación para Bogotá plasmada en el documento oficial: Bogotá más activa: Política Pública de deporte, recreación y actividad física para Bogotá 2009-2019, permitió identificar que las metodologías que se emplean para incluir las voces de los niños y niñas no son claras.

En este aspecto es importante reflexionar sobre el concepto de participación y de participación infantil que tienen los hacedores de política pública. En lo que refiere a la participación, el concepto proporcionado por el jefe del área de recreación realiza un aporte valioso al presentar la importancia que tiene una actitud de participación activa puesto que expresa que participar no solo se da en la toma de decisiones sino al ser protagonistas de la acción. Por otro lado, el coordinador de la localidad lo limita exclusivamente a la toma de decisiones.

Respecto a la participación infantil se incorporan principios claves para tener en cuenta en la conceptualización de participación infantil como: la escucha, la interpretación de sus necesidades, anhelos, gustos y la posibilidad de generar acciones con los mismos niños y niñas; sin embargo, el coordinador local presenta su preocupación por la carencia de espacios para hacer posible esta participación. Afirmación importante para la reflexión que plantea esta investigación, puesto que confirma de nuevo el reto por crear los espacios, mecanismos y metodologías que en la práctica lleven a materializar el derecho de participación de los niños y niñas.

Respecto a la metodología empleada para el diseño y formulación de la política pública de deporte, recreación y actividad física para Bogotá 2009-2019 el jefe del área de recreación expresa que la Política Pública del año 2009 al 2019 se formuló a partir de un 
análisis “orientado por la Universidad de los Andes fue una metodología participativa, de hecho la metodología se llamó: la pelota está en tus manos, porque el ejercicio consistía en que todas las personas que intervenían en la reunión, se hicieron dos reuniones locales después se hicieron unas asociaciones distritales, después hubo una convalidación de esos contenidos a nivel de expertos en cada uno de los sectores: educativo, empresarial, cajas de compensación familiar, etc." (Respuesta dada por Oscar Ruíz en la entrevista). Al indagar si en esta experiencia de la pelota está en tus manos fueron escuchadas las voces de los niños y niñas, se indica que fueron escuchadas pero mediadas por la información que expresaban los padres que llevaban a sus hijos(as), lo cual nos permite inferir que éste espacio de participación no tuvo en cuenta de forma particular o por medio de una adaptación del ejercicio exclusivamente con niños y niñas, para que se escuchen sus voces de forma directa. Respuestas que nos permiten identificar un vacío en los escenarios, metodologías o experiencias que fomenten la participación infantil y que generen aportes importantes en la formulación de políticas públicas que respondan a la satisfacción del derecho a la recreación de los niños y niñas y al diseño de programas y proyectos que tengan en cuenta los gustos, anhelos y necesidades que son expresadas por ellos y ellas.

El jefe de recreación afirma que los hallazgos encontrados en la metodología la pelota está en tus manos si fueron tenidos en cuenta, puesto que de ahí surgen programas como las ludotecas, las areneras, parques infantiles, canchas para mini deportes y el aumento de instalaciones de zonas infantiles tipo laberintos "para que el niño pueda experimentar un poco con su entorno" (Respuesta dada por Oscar Ruíz en la entrevista). Respuesta que nos demuestra la importancia que tiene escuchar las voces de los niños y niñas, al materializar necesidades e ideas innovadoras en el diseño de los programas que responden a una Política Pública que plasme las realidades a transformar de la comunidad.

Si bien, la metodología que se plasma en el documento oficial de la Política Pública, como se verá a continuación, propició los escenarios de participación ciudadana, la experiencia detallada que la entrevista vislumbró, en cuanto al tema que nos convoca de participación infantil, se puede evidenciar que las voces de los niños y niñas en dicho ejercicio de participación no fueron escuchadas directamente. A continuación se presenta 
la metodología de participación empleada para el diseño y formulación de la Política Pública de deporte, recreación y actividad física para Bogotá 2009-2019:

El proceso de construcción de esta política pública se realizó en tres etapas:

a. Se llevaron a cabo las mesas de concertación con la comunidad de las veinte localidades de Bogotá, mediante la realización de dos talleres por localidad, para lo cual se suscribió un convenio con una institución universitaria.

b. Se elaboró y socializó la versión preliminar del documento de política pública, mediante la publicación en el portal www.bogotamasactiva.gov.co

c. Se realizaron sesiones de retroalimentación, ajuste y aprobación del documento de política pública. (Alcaldía Mayor de Bogotá D.C., 2009, p. 16)

El ejercicio de participación que se valora al propiciar escenarios en cada una de las localidades de la ciudad, pero que puede mejorar en lo que refiere a espacios más incluyentes o metodologías particulares que permitan la participación directa de los diferentes sectores poblacionales, en este caso puntal, escenarios para escuchar de forma directa los sentires, anhelos y aportes que los niños y niñas pueden brindar, expresándose por medio del lenguaje del arte: la pintura, la escritura, el teatro; en el lenguaje del juego en sí mismo.

A continuación se presenta una matriz que plasma los hallazgos documentales y de la entrevista en lo que refiere a la metodología empleada para la formulación de la Política Pública de deporte, recreación y actividad física para Bogotá 2009 - 2019. 
Tabla 6

Metodología de participación para la formulación de la Política Pública de deporte, recreación y actividad física para Bogotá 2009 - 2019.

\begin{tabular}{|c|c|c|}
\hline \multirow{2}{*}{ Política } & \multicolumn{2}{|l|}{ Metodología para la formulación } \\
\hline & Documento & Entrevista \\
\hline $\begin{array}{l}\text { Bogotá más } \\
\text { activa: Política } \\
\text { Pública de } \\
\text { deporte, } \\
\text { recreación y } \\
\text { actividad física } \\
\text { para Bogotá } \\
2009-2019 .\end{array}$ & $\begin{array}{l}\text { La pelota está en tus manos: } \\
\text { "metodología que facilitó la amplia } \\
\text { participación, abierta y plural, de la } \\
\text { comunidad agrupada por } \\
\text { localidades, en la cual creamos un } \\
\text { ambiente de confianza y } \\
\text { transparencia. Basándonos en el } \\
\text { principio del respeto mutuo, todos } \\
\text { los aportes fueron valorados por los } \\
\text { participantes y considerados por los } \\
\text { facilitadores para la priorización, de } \\
\text { manera igualitaria. El turno para } \\
\text { hablar y escuchar fue respetado, } \\
\text { gracias a un acuerdo previo } \\
\text { realizado entre todos, en el marco } \\
\text { de la campaña "La pelota está en tus } \\
\text { manos", concebida para educar a } \\
\text { los participantes, con el fin de lograr } \\
\text { una participación activa y } \\
\text { respetuosa. En general, realizamos } \\
\text { talleres y mesas de concertación por } \\
\text { localidad. En primer lugar, } \\
\text { llevamos a cabo cuarenta talleres } \\
\text { (dos por cada localidad), logramos } \\
\text { la participación de más de 5.000 } \\
\text { personas, cuyos aportes fueron } \\
\text { publicados, en su totalidad y de } \\
\text { manera transparente, en el portal } \\
\text { www.bogotamasactiva.gov.co } \\
\text { (Alcaldía Mayor de Bogotá D.C., } \\
\text { 2009, p. 10) }\end{array}$ & $\begin{array}{l}\text { Oscar Ruiz: "Fue una metodología } \\
\text { participativa, de hecho la metodología se llamó: } \\
\text { la pelota está en tus manos, porque el ejercicio } \\
\text { consistía en que todas las personas que } \\
\text { intervenían en la reunión, se hicieron dos } \\
\text { reuniones locales después se hicieron unas } \\
\text { asociaciones distritales, después hubo una } \\
\text { convalidación de esos contenidos a nivel de } \\
\text { expertos en cada uno de los sectores educativo, } \\
\text { empresarial, cajas de compensación familiar, } \\
\text { etc. Y pues se llamó la pelota está en tus manos } \\
\text { porque la persona que iba a hablar se le daba una } \\
\text { pelota, físicamente una pelota ara que hablara e } \\
\text { hiciera sus comentarios para organizar un poco } \\
\text { como el trabajo entonces así se construyó en ese } \\
\text { momento la política." } \\
\text { Entrevistadora: En esa metodología, ¿las } \\
\text { personas que tenían la pelota en las manos } \\
\text { también fueron niños o niñas ofueron adultos o } \\
\text { jóvenes? } \\
\text { Oscar Ruiz: "Hubo de todo por su puesto un } \\
\text { niño de } 580 \text { } 10 \text { años de alguna forma no puede } \\
\text { participar de una manera tan activa sin la } \\
\text { compañía de sus padres, muchos de ellos } \\
\text { estaban acompañados de sus padres y a través } \\
\text { de sus padres expresaban sus opiniones que de } \\
\text { uno u otra forma consideraban o debieran } \\
\text { aportar la constitución de la política también } \\
\text { muchos de los asistentes opinaron porque tenían } \\
\text { hijos pequeños y estaban hábiles de programas } \\
\text { que podían participar." }\end{array}$ \\
\hline
\end{tabular}

Fuente. La autora.

En lo que refiere propiamente a las metodologías de participación infantil que se han empleado para el diseño y formulación de los programas de recreación en la localidad de Usme, la entrevista realizada al coordinador de la localidad de Usme del IDRD, el licenciado Mario Salinas, también nos da argumentos para afirmar que los ejercicios a nivel de mecanismos o escenarios de participación infantil están en proceso de 
consolidación, puesto que como nos damos cuenta en la cronología de reconocimiento que hace la Ley en Colombia, aún es un ejercicio muy nuevo. El licenciado Mario Salinas expresa "veo con gran tristeza que no hay espacios, si hay comités de infancia a nivel de las alcaldías pero faltan que esos niños tengas mejores espacios más propicios para participar" el coordinador local del IDRD expresa que los proyectos y programas nacen de la institución y son diseñados por el nivel central que es Coldeportes, pero que no son los niños o niñas los que participan para hacer parte de dichos programas: "proyectos que nazcan de la institución si los hay pero no donde fomenten la participación ni de acuerdo a lo que los niños digan si no que ya están estipulados desde acá"; expresiones que evidencian que la voz de los infantes es interpretada por los adultos y que son las instituciones quienes elaboran los programas dirigidos a los niños y niñas de la localidad de Usme desde un enfoque de arriba hacia abajo (top-down). Esta realidad invita a re-crear las metodologías, escenarios y mecanismos que la participación infantil tiene como reto en un Estado de derecho como lo es el colombiano.

\section{Caracterización socioeconómica de los niños y niñas beneficiarios.}

También, se encontró que frente a la caracterización socioeconómica los niños y niñas beneficiarios de la ludoteca Uval entre las edades de 6 a 12 años son en un $67 \%$ de sexo femenino y un $33 \%$ de sexo masculino, se cuenta con porcentajes de todos los años de las edades que abarca el rango, al igual que en los diferentes grados escolares, oscilando de primero a séptimo, el $100 \%$ de los niños y niñas se encuentra estudiando y en su mayoría en una institución pública. 
Figura 5. Sexo de los niños y niñas que participaron en el taller.

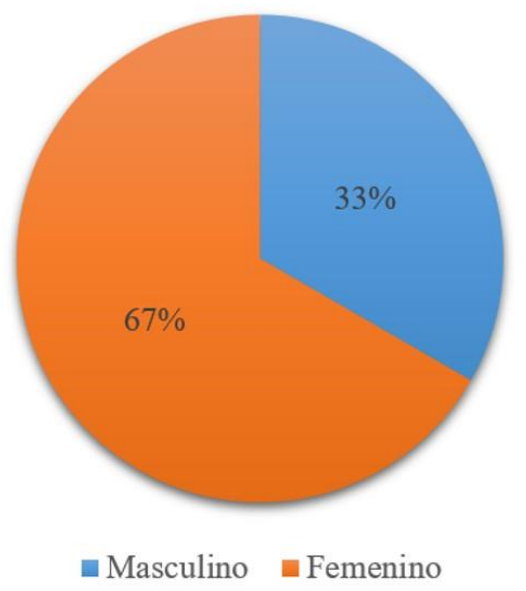

Fuente. Elaboración propia.

Figura 7. Nivel escolar de los niños y niñas que participaron en el taller.

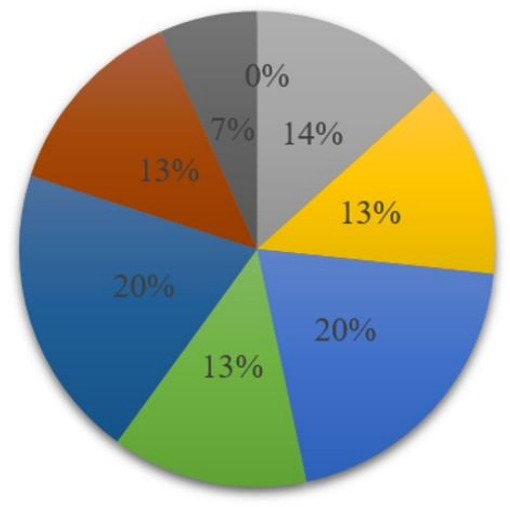

Ninguno $\square 0 \square 1 \square 2 \square 3 \square 4 \square 5 \square 6 \square 7$

Fuente. Elaboración propia.
Figura 6. Edad de los niños y niñas que participaron en el taller.

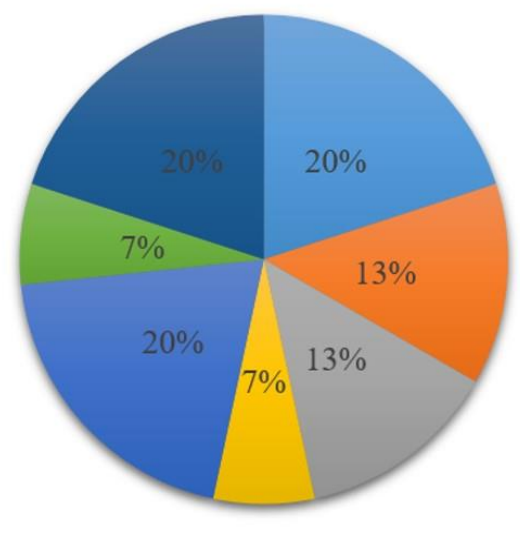

घ $\square 7 \square 8 \square 9 \square 10 \square 11 \square 12$

Fuente. Elaboración propia.

Figura 8. Tipo de institución en la que estudia el niño o niña.

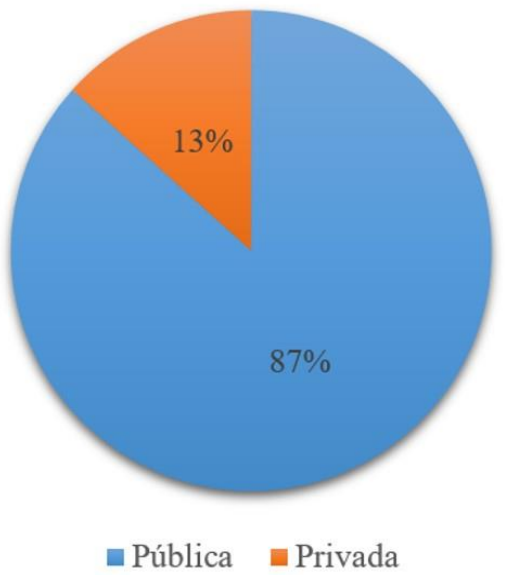

Fuente. Elaboración propia.

La mayoría de familias están integradas por padre y madre, solo un 7\% está integrada por hermanos y tíos, solamente un $13 \%$ de familias son oriundas de Bogotá el $87 \%$ restante es procedente de lugares diferentes del país, lo cual nos indica una realidad de familias que se han desplazado de sus lugares de origen a la ciudad; de las cuales se evidencia la presencia del grupo étnico Pijaos, comunidad indígena colombiana que provienen del 
departamento del Tolima y otros territorios aledaños y un $13 \%$ de víctimas del conflicto armado.

El $100 \%$ de familias vive en un área rural, el $87 \%$ viven en estrato ${ }^{23}$ uno y el $13 \%$ restante en estrato dos, lo que significa que la mayoría de niños y sus familias viven en un estrato socioeconómico bajo-bajo que evidencia un estado de pobreza económica, el cual se asocia a limitaciones que impide a la familia acceder a una vivienda de calidad y con ella a condiciones básicas para vivir dignamente; ello es un indicador que se asocia a la falta de oportunidades para que los niños y niñas se desarrollen plenamente, puesto que ¿cómo con los niveles crecientes de pobreza y desigualdad que existen, es posible hablar de ir más allá de satisfacer las necesidades básicas, para pasar a un plano en el que todos y todas tengan la oportunidad de potencializar sus diferentes dimensiones como personas?.

\section{Prácticas y necesidades recreativas.}

Las niñas en los dibujos y escritos indican que en el sector de recreación deportiva, les gusta: jugar fútbol y natación, lo cual se puede potencializar con la oferta de escuelas de formación deportivas en dichas disciplinas que permitan cubrir su territorio, empleando estrategias como una ruta que movilice a los niños y niñas interesadas a los lugares donde la administración local desarrolla dicha oferta. En el sector de recreación artística y cultural les gusta bailar, cantar y escribir, se puede proponer un proyecto de formación artístico cultural que fortalezca las prácticas de creación literaria, la cual iría hilada a incentivar la lectura, clases de danzas y canto que potencialicen las prácticas que refieren.

\footnotetext{
${ }^{23}$ La estratificación socioeconómica en Colombia es una clasificación de inmuebles que se utiliza como instrumento de focalización geográfica para el cobro diferencial de los servicios públicos domiciliarios en un esquema de subsidios cruzados a la demanda. Se han establecido históricamente seis estratos identificados de acuerdo a las características de la vivienda y del entorno, como indicador indirecto de la capacidad económica de quienes los habitan. De esta manera, la calidad de la vivienda se ha tomado como aproximación a la calidad de vida de sus habitantes (DNP, 2008, p. 11).
} 
En lo que refiere a otras prácticas recreativas se identifica que la mayoría de niñas la categoría que indicó es el juego, les gusta jugar a saltar laso, a las escondidas, a las cogidas, a la gallinita ciega y a la profesora. Estas prácticas muestran la vivencia plena y cotidiana del juego en las niñas, en la esencia de lo que representa el juego para ellas como experiencia de vida, natural, y autentica, sin ningún tipo de motivación o imposición externa; en este escenario lo que se recomienda es proponer estrategias al interior de las instituciones educativas y de los escenarios de encuentro como la Ludoteca, el parque y la casa que incentiven a esa vivencia plena del juego, proporcionando los tiempos, los escenarios seguros, la socialización de juegos tradicionales que fortalezcan el lazo de tradición oral que se puede generar con el adulto y algunos elementos que permitan la exploración desde el juguete.

También se identifica la presencia de otros sectores de la recreación como:

Recreación ambiental: cuando las niñas expresan de forma escrita y gráfica que les gusta: Ver la naturaleza. Plantar y dibuja un árbol con frutos y a ella junto a él; lo cual es muestra de una conciencia ambiental que las niñas tienen respecto a su entorno, siendo el área rural en la que habitan, toma un valor fundamental el estimular dichas prácticas, para que se conviertan en hábitos y en una cultura de preservación de su entorno; en este aspecto se recomienda incentivar ejercicios desde la educación ambiental, promoviendo campañas y jornadas de siembra, de reciclaje, entre otras actividades.

Recreación comunitaria: en este sector refieren que les gusta participar en grupo, lo que nos permite incentivar las actividades grupales como procesos de socialización que formen en la actitud de trabajo en equipo, comunicación y valores de solidaridad y respeto, escenarios que actualmente por los hábitos de vida que ha generado la tecnología ha traído estilos de vida sedentarios y la preferencia de juegos electrónicos, los cuales en su mayoría de veces se juegan en soledad; aquí es importante resaltar la característica del territorio, al ser en un $100 \%$ rural, lo cual permite generar en los niños y niñas de la Ludoteca del barrio Uval un estilo de vida más activo, siendo esta una oportunidad que se tiene para fortalecer la iniciativa de prácticas recreativas en comunidad. 
Los resultados hallados con los niños arrojan: en el sector de recreación deportiva les gusta jugar fútbol. Lo que nos indica la falta de oportunidades de los niños en lo que respecta a tener el conocimiento de otros deportes, debido a que el fútbol es el deporte más popular, puesto que muchas veces no requiere de un escenario deportivo, sino simplemente de un lugar que delimita dos porterías con cualquier elemento, desde piedras hasta los mismos zapatos. Esta práctica llama la atención en lo que refiere a la oferta que se está generando para los niños del barrio Uval en el sector deportivo, si bien no se cuenta en el barrio con escenarios y elementos que permitan la práctica de otros deportes, si se puede proponer ejercicios predeportivos con elementos y escenarios que desde la recursividad presenten otras opciones, por ejemplo el kickball, el balón mano, el squash, el atletismo, ente muchos otros deportes que sólo necesitan de la imaginación y creatividad para adaptar los escenarios y elementos con los que se cuenta o con los que se puede invertir desde el gobierno local para equipar este territorio.

En el sector de recreación artística y cultural un solo niño expresa de forma gráfica y escrita que le gusta escribir y leer, hallazgo que nos refuerza el planteamiento anterior que evidencia la falta de oportunidad de los niños al no contar con una oferta, en este caso desde el sector artístico cultural, lo que los lleva a realizar las mismas prácticas que se limitan al fútbol, para el caso puntual. En este caso es importante generar una oferta de un programa artístico cultural que implemente estrategias que incluyan las diferentes disciplinas artísticas para dar a conocer las prácticas y descubrir talentos y potencializarlos.

Se identifica otra práctica: la actividad de manejar o conducir carro, la cual permite reconocer el rol que asume el niño gracias al juego y a la capacidad de imaginación. También se identifica la presencia de otros sectores como el de recreación comunitaria en categorías como: no hacer guerra, paz, ayudar a los demás. Lo que nos indica que el bien común lo asocian con la recreación como formas de interacción con los otros, así como se identifica el interés de superar una realidad nacional de violencia que pueden observar o que han vivido. 
Por otra parte, en un $100 \%$ los niños y niñas se recrean en familia, integrando a los diferentes miembros que la conforman; lo que nos permite inferir el valor que las niñas y niños dan a la recreación comunitaria en lo que refiere a sus prácticas grupales y a los nobles intereses de ayudar a los otros.

Las dificultades que señalan son en un $63 \%$ la falta de tiempo, el $31 \%$ la falta de dinero y el 6\% la ausencia de escenarios adecuados; respuestas emitidas por los acudientes y las cuales nos indican que las personas asocian que las actividades recreativas implican el gasto de dinero, barrera que desde una perspectiva la podemos leer como un imaginario social y en la cual se puede trabajar desde el conocimiento e interiorización del concepto de recreación en sus vidas, para lo cual no se requiere obligatoriamente el dinero, sino la vivencia en plenitud de momentos que muchas veces se han olvidado, como el juego en familia, el compartir de historias de los adultos a los niños, la lectura, la actividad física como caminar, el encuentro en familia para hablar alrededor del alimento; entre muchas y tan cotidianas prácticas las cuales no se limitan al dinero o al tiempo; sino a la conciencia de disfrute de la vida.

Sin embargo estas respuestas también se pueden analizar desde una perspectiva del desarrollo de libertades que nos propone Sen, donde la pobreza económica si se comprende como una limitante en la medida en que la elección de alternativas de bienestar se ve en un segundo plano, dando prioridad a suplir sus necesidades básicas como la alimentación, de ahí que Sen comprende una “concepción satisfactoria de desarrollo debe ir mucho más allá de la acumulación de riqueza y de1 crecimiento de1 producto nacional bruto y de otras variables relacionadas con la renta. Sin olvidar la importancia de1 crecimiento económico, debemos ir mucho más allá” (Sen, 2000, p. 30), por eso el papel de la libertad se sustenta en la eficacia de la que se dotan las personas para llevar el tipo de vida que valoran, desarrollándose desde sus deseos y expectativas. 


\section{Preferencias recreativas de los niños y niñas de acuerdo a los sectores de la recreación.}

Finalmente, en lo que refiere a los resultados de las preferencias de las prácticas recreativas en el sector deportivo las niñas expresan que les gustaría nadar, en expresiones como "Quisiera nadar todos los días con mis amigas y que sea gratis.", lo cual propone un reto para la administración local y la coordinación de los programas del IDRD al generar una cobertura en el territorio del barrio El Uval; para que se permee a toda la comunidad las iniciativas de escuelas de formación deportiva, generando una inversión en equipamentos, escenarios y talento humano o desarrollando estrategias de movilidad para lograr la cobertura a esta población.

Se da continuidad en el sector artístico cultural a la disciplina artística de la danza como actividad que le gustaría hacer para recrearse, en expresiones como: "Bailar" y "Me gustaría que las lecciones de bailes a los que les gustaría bailar canciones o bailar." Hallazgo que resalta la importancia de tener en cuenta la recomendación realizada en el apartado anterior, de implementar un programa de formación artística en las disciplinas de la danza y el canto; esta propuesta en la que sería importante presentar otras disciplinas artísticas como la literatura, el teatro, las artes visuales y plásticas, el cine, para diversificar una oferta que genere oportunidades de exploración, práctica y conocimiento de un mundo inmenso de expresiones que no se puede limitar por su condición socioeconómica, puesto que el medio en el que viven no les brinda otras propuestas.

Nuevamente se resalta el juego como la práctica que les gustaría hacer para recrearse y aparece una actividad que hace referencia a inventar algo para la humanidad, lo cual lo asocian con la tecnología y con la construcción de un parque; lo que señala que las niñas asumen la recreación en su sentido más esencial, en re-crear cada experiencia de la vida misma que no se esquematiza en una práctica deportiva, sino en la diversidad de actividades de creación que en sí mismas, al ser elegidas en plena libertad, ya producen un sentido de recreación en sus vidas. Quizás cuando somos adultos dejamos de sentir que 
cada acción que realizamos nos permite experimentar goce y pasamos a cargar de obligaciones nuestros días, sin reflexionar en la profesión o el trabajo que elegimos para convertirse en un proyecto de vida que colme nuestras expectativas y que día a día nos recree, tristemente dejamos de ser niños y es en ejercicios como estos, donde escuchamos sus voces, que recordamos el valor de la perspectiva desde la cual veíamos nuestro mundo, desde una lectura positiva, desde la alegría y el regocijo; es por tal motivo que como adultos tenemos mucho que aprender de los niños para incorporarlo en nuestras vidas y en la apuesta del bien común.

Por otra parte, el deseo de construir un parque da cuenta de la solución a la necesidad que evidencian en su territorio y al imaginario en el que se encasillan los escenarios recreativos.

También se identifica la presencia de otros sectores de la recreación como:

Recreación turística: cuando expresan que les gustaría salir al parque y a pasear, "Me gustaría aser cosas diferentes salir a pasiar con mi familia y con mis amigos y con las profesoras y pasarlas bien.” Esta preferencia identificada nos permite recomendar en el diseño del programa recreativo incluir un proyecto que responda a la recreación turística desde la programación de caminatas, pasa días y viajes que sean trasversales a la preferencia del cuidado del medio ambiente por medio de actividades de ecoturismo.

Recreación comunitaria: jugar todas participando. De nuevo se evidencia el valor que las niñas dan al juego y al compartir en comunidad, donde el concepto de participación se puede interpretar como la acción que las involucra en el desarrollo de la práctica recreativa.

Finalmente, se identifica que una niña asocia la actividad recreativa que le gustaría hacer con el hecho de ayudar a su mamá a hacer oficio: "A mí me gusta hacer oficio con mamá" expresión que nos lleva a reflexionar sobre la influencia del contexto socioeconómico y 
de los modos de vida ${ }^{24}$ que las niñas han asumido en sus hogares en la cotidianidad de su vida, lo cual resalta de nuevo la perspectiva de desarrollo y libertad de Sen, donde "la liberación del hambre y la satisfacción de las necesidades básicas ocupan un lugar importante.” (Sen, 2000, p. 23) para el desarrollo, que va más allá de una perspectiva de crecimiento económico, medio por el Producto Interno Bruto (PIB) de un país a un desarrollo pleno de las capacidades de las personas, de asumir el desarrollo humano como "Un proceso mediante el cual se busca la ampliación de las oportunidades para las personas, aumentando sus derechos y sus capacidades... las garantías de los derechos humanos y otros que son reconocidos por la gente como necesarias para ser creativos y vivir en paz.” (Naciones Unidas, 2008)

La mayoría de niñas expresa que las actividades le gustaría hacerlas con sus amigas, lo que nos indica la importancia que tiene el grupo social inmediato a su cotidianidad y el vínculo que identifican. La categoría de familia, mamá, papá y hermanos, se identifica en las actividades de juego y del sector de la recreación turística. En la categoría de la comunidad se identifica un grupo de actores sociales que genera vínculo quizás por su relación cotidiana con las niñas, son las profesoras, por el tiempo que permanecen en la escuela y en la participación de otros escenarios como la Ludoteca, donde identifican éste actor social.

Los niños a nivel del sector deportivo de la recreación sólo expresan la actividad de jugar fútbol, no mencionan actividades del sector de la de recreación artística y cultural y se identifica la presencia de otros sectores de la recreación como:

Recreación ambiental: los niños expresan que les gustaría plantar con la familia, cuidar las zonas verdes y ríos.

Recreación turística: cuando expresan que les gustaría ir a Florencia.

\footnotetext{
${ }^{24} \mathrm{El}$ concepto modo de vida hace referencia a la influencia socioeconómica en las actividades de la vida cotidiana de las personas y sociedades. "La estructura económico-social y el grado de desarrollo de la cultura en cada lugar y época histórica, se expresan en la actividad humana colectiva como su modo de vida." (González, 2004, s/p)
} 
Similar al caso aislado que nos responden las niñas, también hay un niño que expresa que le gusta ayudar a su mamá a hacer oficio, como actividad que le gustaría hacer para recrearse. A diferencia de las niñas, los niños en la categoría de población con quienes les gustaría hacer las actividades para recrearse mencionan a la familia: mamá, papá y hermanos, se identifica actividades de la recreación ambiental y turística, al igual que las niñas, donde, como se indicó anteriormente, se recomienda diseñar programas recreativos que incluyan actividades de ecoturismo para cruzar los dos sectores y fortalecer los hábitos de cuidado del medio ambiente, prioridad en la agenda no sólo nacional sino mundial, que responde a los impactos ambientales y sociales que ha generado la carrera sin límite del desarrollo en clave de crecimiento económico.

Las respuestas anteriores nos permiten analizar el por qué nombran actividades similares y tan concretas, lo que nos lleva a concluir la influencia de su contexto socioeconómico, el cual puede inferir por las oportunidades que oferta su territorio y su modo de vida y los imaginarios sociales que se han construido desde sus familias en las practicas recreativas.

\section{Conclusiones.}

Este recorrido nos deja el reto de crear metodologías que permitan una participación infantil auténtica, que podamos innovar en estrategias que permitan escuchar las voces de los niños y niñas en los temas que los convocan, para diseñar políticas públicas y programas que respondan a sus necesidades y al goce de sus derechos, en este caso el derecho a la recreación. Lo anterior nos invita a repensar la participación infantil desde la construcción de metodologías que se apoyen del lenguaje universal de los niños y niñas: el juego y de expresiones artísticas que permitan plasmar sus sentires y anhelos. Por otra parte resalta el valor que tiene la participación infantil como vehículo para hacer realidad la construcción de un mundo mejor, así como el potencial creativo de los niños y niñas que los lleva a imaginar diferentes realidades que implica contar con el potencial 
innovador y optimista del niño(a), quien se atreve a soñar, su optimismo supera el mundo cuadriculado que el adulto muchas veces no se atreve a ver redondo.

La participación infantil fortalece la democracia desde un proceso paulatino, al formar a los niños y niñas en espacios de participación ciudadana, para que al crecer sean adultos que no se limiten solamente a votar, sino que sean actores sociales que se empoderen de las tomas de decisiones que se plasman en las políticas públicas, al no sólo ser parte de su agenda o formulación, sino de su puesta en marcha en su comunidad y así, ser protagonistas de la transformación de su realidad. Demanda formarlos en el valor de la tolerancia, igualdad y solidaridad; en los ejercicios de participación se aprende a escuchar al otro, a comprenderlo, a entenderlo, a reconocerlo, a salir del estado individual para pasar a un encuentro con el otro, a construir con el otro y estos valores sin duda hace mejores ciudadanos y ciudadanas que busquen el tan anhelado bien común.

En lo que refiere a las características que se derivan de las prácticas, preferencias y necesidades recreativas de los niños y niñas de la Ludoteca del barrio Uval de la Localidad de Usme, a nivel deportivo se evidenció que el fútbol y la natación son los deportes favoritos de los niños y niñas, en el sector artístico cultural el baile, el canto y la escritura para las niñas, en la recreación ambiental el cuidado a la naturaleza y en la turística la visita a sus lugares de procedencia y paseos en familia; éste tipo de prácticas y preferencias concretas nos lleva a identificar las necesidades, las cuales están marcadas por su contexto socioeconómico, el cual puede inferir por las oportunidades que oferta su territorio y su modo de vida y los imaginarios sociales que se han construido desde sus familias en las prácticas recreativas.

Se recomienda diseñar programas que respondan a los sectores de la recreación deportiva, artística cultura, ambiental y turística; mediadas por ejercicios de recreación comunitaria que permitan el encuentro con los otros: sus familias y amigos; donde el diseño de proyectos recreativos permita relacionar dichos intereses, proponiendo un proyecto de actividades ecoturísticas el cual puede potencializar las oportunidades de un 
territorio rural, además que responde a tres de los sectores mencionados: ambiental, turístico y comunitario y proyectos de formación deportiva y artística, que si bien, busquen responder a la oferta de las disciplinas deportivas y artísticas expresadas; también oferten otras alternativas; puesto que por la condición socioeconómica se infiere que los niños y niñas de la Ludoteca del barrio Uval no cuentan con una oferta diversa y así mismo se inclinan por lo que conocen para elegir, por tal motivo es un reto para las instituciones locales que les compete la temática tratada, re-crear las estrategias que respondan al goce efectivo del derecho a la recreación, para potencializar todas la capacidades de los niños y niñas y propiciar así el desarrollo humano integral que supere su condición económica o social a partir de propuestas creativas y recursivas o de inversiones que incrementen la cobertura y equipamiento que potencialicen este territorio.

\section{Referentes.}

Aguilar, C. \& Lima, M. (2009). ¿Qué son y para qué sirven las Políticas Públicas? Revista Contribuciones a las Ciencias Sociales, España, Universidad de Málaga, septiembre de 2009 en https://goo.gl/FlELVw Consultado el 10 de diciembre de 2016.

Aguilar, L. (1992). El estudio de las Políticas Públicas. México: Miguel Ángel Porrúa grupo editorial.

Alcaldía Mayor de Bogotá D.C. (2009). “Bogotá más activa”. Política Pública de Deporte, Recreación y Actividad Física para Bogotá 2009-2019. Bogotá: Panamericana Formas e Impresos S.A.

. (2012). Plan de Desarrollo 2012-2016: Bogotá Humana. Disponible en https://goo.gl/fOvE6Z Consultado el 26 de febrero de 2014.

(2016). Plan de Desarrollo 2016-2020: Bogotá mejor para todos. Bogotá. Disponible en https://goo.gl/Ay98Xq Consultado el 1 de noviembre de 2016. 
Apud, A. (s/f). Participación infantil. UNICEF. Disponible en https://goo.gl/r23ArA Consultado el 23 de octubre de 2014.

Asamblea General de las Naciones Unidas. (1989). Convención sobre los Derechos del Niño. Disponible en https://goo.gl/utM2MP Consultado el 25 de octubre de 2014.

Banco Mundial. (2010). La formulación de políticas en la OCDE: Ideas para América Latina. Disponible en https://goo.gl/tvYNky Consultado el 21 de abril de 2014.

Barra, M. (s/f) El Estudio de la Factibilidad Política de las Políticas Públicas. Revista Políticas Públicas, Chile, Universidad de Santiago de Chile, 108 - 129 en https://goo.gl/GAoAWv consultado el 23 de abril de 2014.

Burpee, G. Heinrich, G \& Zemanek, R. (2008). Desarrollo humano integral (DHI): Concepto y Marco. USA: Catholic Relief Services.

Coldeportes. (2004). Plan Nacional de Recreación 2004-2009. Bogotá: Imprenta Nacional. . (2009). Plan Decenal del Deporte, la Recreación, la Educación Física y la Actividad Física 2009 - 2019. Disponible en https://goo.gl/yjtLwx Consultado el 26 de febrero de 2014.

Comité Operativo Distrital de Infancia y Adolescencia (CODIA). (2011). Política de Infancia y Adolescencia en Bogotá D.C. 2011- 2021. Bogotá: Alcaldía Mayor de Bogotá D.C.

Constitución Política de Colombia. (1991).

Decreto 121 de 2012. Por medio del cual se crea el Consejo Consultivo Distrital de niños, niñas y adolescentes y los Consejos Locales de niños, niñas y adolescentes. Disponible en https://goo.gl/IUL2V2 consultado el 25 de octubre de 2014.

Departamento de Planeación Nacional (DNP). (2008). Evaluación de la estratificación socio-económica como instrumento de clasificación de los usuarios y herramienta de asignación de subsidios y contribuciones a los servicios públicos domiciliarios. 
Bogotá: DNP. Disponible en https://goo.gl/DqHLiI consultado el 5 de diciembre de 2016.

Departamento de Planeación Nacional (DNP) \& Escuela Superior de Administración Pública (ESAP). (2012). Guías para la gestión pública territorial: Planeación para el desarrollo integral en las entidades territoriales El plan de desarrollo 2012-2015. Disponible en https://goo.gl/zULWlf

El Sahili, L. \& Munguía, G. (2011). Desarrollo Humano. Guanajuato: Universidad de Guanajuato.

Escobar, A. (2006). La invención del Tercer Mundo. Bogotá: Editorial Norma.

González, M., Charria, B., Pérez, J., Becerra, L., Gómez, J., Martínez, J. \& Romero, J. (2007). Fundamentos, política, instrumentos y desarrollo de la proyección social y extensión universitaria en la USTA. Bogotá: Universidad Santo Tomás.

González, U. (2004). El modo de vida en la comunidad y la conducta cotidiana de las personas. Revista cubana de Salud Pública 31. Disponible en https://goo.g1/H9EOpW Consultada el 10 de diciembre de 2016.

Hernández, A. (2002). Republicanismo contemporáneo: igualdad, democracia deliberativa y ciudadanía. Bogotá: Siglo del hombre editores, CIDER, Universidad de los Andes.

ICBF \& FUNLIBRE. (2003). Derechómetro: Percepción Infantil sobre vulneración de Derechos. Disponible en https://goo.gl/N7g33J Consultado el 31 de Agosto de 2014.

Ley 181 de 1995. Por el cual se dictan disposiciones para el fomento del Deporte, la Recreación, el aprovechamiento del Tiempo Libre y la Educación Física y se crea el Sistema Nacional del Deporte. Disponible en https://goo.gl/v9ZqlG Consultado el 26 de febrero de 2014.

Ley 1098 de 2006. Por la cual se expide el Código de la Infancia y la Adolescencia. Disponible en https://goo.gl/93uX44 Consultado el 24 de octubre de 2014. 
López, L., Montes, M. \& Espejo, E. (2008). Prácticas y Perspectivas de la Recreación en Bogotá. Bogotá: Universidad Santo Tomás.

Martínez, M. (2009). Dimensiones Básicas de un Desarrollo Humano Integral. Polis, Revista de la Universidad Bolivariana 8, (23). Disponible en https://goo.gl/HNC8Lc Consultado el 21 de abril de 2014.

Martinez, V. \& París, S. (2006). Amartya K. Sen y la globalización. Castellón de la Plana: Universitat Jaume.

Max-Neef, M. (1993). Desarrollo a escala humana. Barcelona: Icaria Editorial. Consultado en https://goo.gl/QtFP5f el 24 de marzo de 2014.

Ministerio de Educación, Cultura y Deporte de España. (2003). Metodología del juego. Madrid: Gráficas VARONA S.A.

Mora, J. (2002). Introducción a la Teoría del Consumidor. De la preferencia a la estimación. Cali: Universidad ICESI.

Muñoz, L. (2003). Educación Psicomotriz. Hacia un concepto de movimiento Humano. Armenia: Ed. Kinesis.

Naciones Unidas. (2008). Programa de Naciones Unidas para el Desarrollo. Disponible en https://goo.gl/c4TC6d Consultado el 26 de febrero de 2014.

Omeñaca, R. \& Ruiz, J. (2004). Juegos cooperativos y Educación Física. Barcelona: Editorial Paidotribo.

Osorio, E. (octubre, 2005). La recreación y sus aportes al desarrollo humano. I Congreso departamental de recreación de la Orinoquia colombiana. Villavicencio, Meta. Disponible en https://goo.gl/JeJuCY Consultado el 25 de octubre de 2014.

Perinat, A. (2000).Psicología del desarrollo. Desarrollo y coordinación del movimiento. Barcelona: Editorial UOC. 
. (2003). Psicología del desarrollo: un enfoque sistémico. España: Editorial UOC.

Pugmire-Stoy, M. (1996). El juego espontáneo: vehículo de aprendizaje y comunicación. Madrid: Narcea S.A. Ediciones.

Secretaría Distrital de Planeación. (2009). Conociendo la localidad de Usme: Diagnóstico de los aspectos físicos, demográficos y socioeconómicos. Bogotá: Alcaldía Mayor de Bogotá. D.C.

. (2011). 21 Monografías de las Localidades. Distrito Capital 2011: Diagnóstico de los aspectos físicos, demográficos y socioeconómicos Localidad número 5 Usme. Bogotá: Alcaldía Mayor de Bogotá D.C.

Sen, A. (2000). Desarrollo y Libertad. Barcelona: Editorial Planeta.

Shadowxfox (2013). Distrito Capital de Bogotá - Usme.svg. Disponible en https://goo.gl/amHELY Consultado el 19 de noviembre de 2016.

Tonucci, F. (2006). La ciudad de los niños. Italia: Istituto di Psicología del CNR.

Trilla, J. \& Novella, A. (2005). Educación y participación social de la infancia. España: Organización de Estados Iberoamericanos (OEI).

Velásquez, F. \& González, E. (2003). ¿Qué ha pasado con la participación ciudadana en Colombia? Bogotá: Fundación Corona. 